\title{
Ibrutinib in CLL/SLL: From bench to bedside (Review)
}

\author{
FUMING ZI ${ }^{1-3}$, LI YU ${ }^{1-3}$, QINGZHI SHI ${ }^{1-3}$, AIPING TANG ${ }^{1-3}$ and $\mathrm{JING} \mathrm{CHENG}^{1-3}$ \\ ${ }^{1}$ Department of Hematology, The Second Affiliated Hospital of Nanchang University; \\ ${ }^{2}$ Institute of Hematology, Nanchang University; ${ }^{3}$ Key Laboratory of Hematology, Nanchang, Jiangxi 330006, P.R. China
}

Received December 18, 2018; Accepted August 1, 2019

DOI: $10.3892 /$ or.2019.7364

\begin{abstract}
B-cell receptor (BCR) signaling is important for the development and maturation of normal B-cells and plays a key role in B-cell malignancies. Bruton's tyrosine kinase (BTK), a crucial terminal kinase enzyme in BCR signaling, has emerged as an attractive target and has been successfully applied in the treatment of hematological malignancies. Ibrutinib, a BTK inhibitor, has demonstrated marked efficacy and tolerability in treatment-naïve, relapsed/refractory chronic lymphocytic leukemia/small lymphocytic lymphoma (CLL/SLL) and mantle cell lymphoma (MCL). Ibrutinib has been approved by the Food and Drug Administration (FDA) for the treatment of CLL/SLL, MCL, marginal zone lymphoma and Waldenström macroglobulinemia and by the China FDA for the treatment of CLL/SLL and MCL. Clinical trials of ibrutinib, as a single agent or combined with chemoimmunotherapy and other promising novel agents in the treatment of B-cell malignancy therapy, such as diffuse large B-cell lymphoma, follicular lymphoma, multiple myeloma, primary and secondary CNS lymphoma and acute lymphoblastic leukemia, T-cell lymphoma and myelodysplastic syndrome, are ongoing (https://clinicaltrials. gov/). The aim of the present review was mainly to cover the clinical developments regarding the use of ibrutinib in the treatment of CLL/SLL, as well as its safety and toxicity profile.
\end{abstract}

\section{Contents}

1. Introduction

2. BCR/BTK signaling pathway in B-cell malignancies

3. Drug-drug interactions (DDIs)

4. Application of ibrutinib in CLL/SLL

5. Ibrutinib resistance and management

6. Side effects and management

7. Conclusion

Correspondence to: Dr Jing Cheng, Department of Hematology, The Second Affiliated Hospital of Nanchang University, 1 Minde Road, Nanchang, Jiangxi 330006, P.R. China

E-mail: chengjing818@126.com

Key words: ibrutinib, Bruton's tyrosine kinase, chronic lymphocytic leukemia, small lymphocytic lymphoma, side effects, atrial fibrillation, bleeding

\section{Introduction}

The B-cell receptor (BCR) signaling pathway plays an important role in maintaining cellular functions such as proliferation, selection, maturation, apoptosis and differentiation of normal B lymphocytes $(1,2)$. Aberrant activation of the BCR signaling pathway is a common hallmark of several B-lymphoid malignancies. Bruton's tyrosine kinase (BTK), a non-receptor tyrosine kinase that belongs to the tyrosine kinase expressed in hepatocellular carcinoma (TEC) family of kinases, is a crucial terminal kinase enzyme in the BCR signaling pathway (3). This downstream signal transduction protein acts as an important effector molecule in governing B-cell development, differentiation, survival and function. Recently, BTK has emerged as a novel target in the treatment of B-cell malignancies (4).

Ibrutinib, a potent, orally administered BTK inhibitor, has demonstrated promising effectiveness in several B-cell malignancies and autoimmune diseases in preclinical models and clinical trials (5). Ibrutinib has been approved by the Food and Drug Administration for mantle cell lymphoma (MCL) in November 2013, for chronic lymphocytic leukemia or small lymphocytic lymphoma (CLL/SLL) in July 2014, and for Waldenström macroglobulinemia (WM) in January 2015 (6-8). The present review includes three main topics: i) The BCR/BTK signaling pathway in B-cell malignancies; ii) the clinical application of ibrutinib in CLL/SLL; and iii) the side effects of ibrutinib and their management.

\section{BCR/BTK signaling pathway in B-cell malignancies}

The BCR signaling pathway plays an important role in the development and maturation of B cells. The BCR consists of membrane-bound immunoglobulin $(\mathrm{mIg})$ non-covalently associated with a heterodimer of $C D 79 a(\operatorname{Ig} \alpha)$ and $C D 79 b(\operatorname{Ig} \beta)$, which contains the immunoreceptor tyrosine-based activation motif (ITAM) (9). Following binding of the mIg, signals are transduced across the plasma membrane, leading to phosphorylation of the ITAM primarily by Src-family tyrosine kinases (SFKs), such as Lyn. Phosphorylated ITAM leads to SFK binding by Src-homology 2 (SH2) domains (9). This binding, results in the activation and phosphorylation of spleen tyrosine kinases (SYKs) (10). Once Syk is activated, the BCR signal is transduced through a group of proteins associated with the adaptor protein, such as B-cell adaptor for phosphoinositide3-kinase (BCAP), B-cell linker (Blnk) and its downstream 


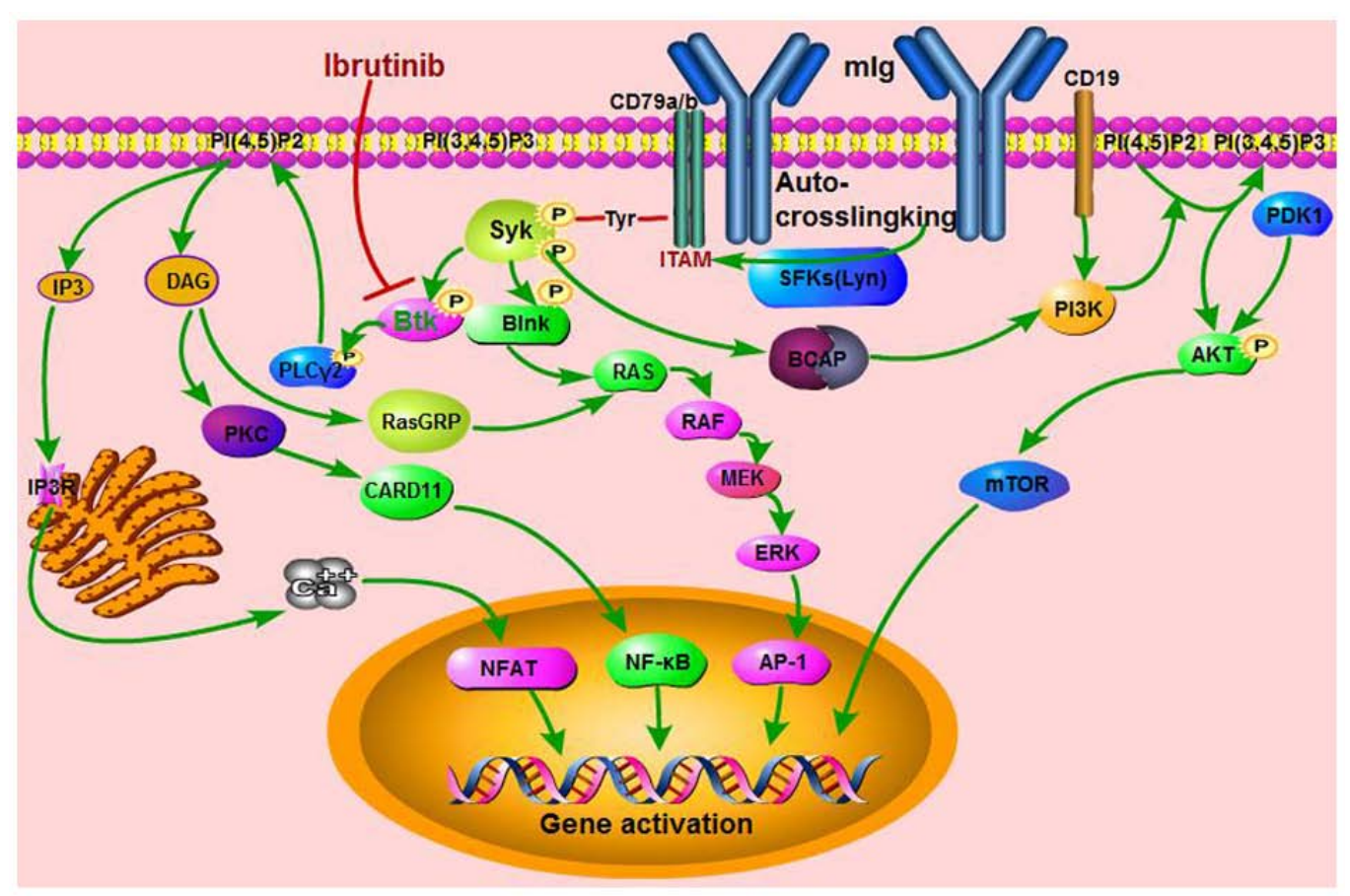

Figure 1. The pathways of BCR/BTK signaling cascade. BCR, B-cell receptor; BTK, Bruton's tyrosine kinase.

signaling components, BTK and phospholipase C $\gamma 2$ (PLC $\gamma 2)$ $(2,9)$. When phosphorylated by Syk, Blnk recruits BTK and PLC $\gamma 2$. After their recruitment, Btk phosphorylates PLC $\gamma 2$, which then cleaves the phosphoinositide phosphatidylinositol 4,5-bisphosphate [PI(4,5)P2], generating inositol triphosphate (IP3) and diacylglycerol (DAG) $(2,9,10)$. IP3 binds to the IP3 receptor (IP3R) in the membrane of the endoplasmic reticulum to facilitate the mobilization of calcium ions, which leads to the activation of nuclear factor for activated T-cells (NF-AT) $(2,9)$. DAG activates protein kinase C (PKC) and its downstream substrates caspase recruitment domain 11 protein (CARD11) and subsequently initiates NF- $\mathrm{KB}$ signaling $(2,10)$. In addition, DAG also binds to Ras guanyl nucleotide-releasing protein (RasGRP) and activates the RAS/RAF/MEK/ERK signaling pathway (9-11). With the assistance of PI3K, the activity of which is localized to the plasma membrane by a lipid-binding domain or by recruitment to CD19 or BCAP, $\mathrm{PI}(4,5) \mathrm{P} 2$ generates phosphatidylinositol 3,4,5-triphosphate [(PI(3,4,5)P3)], which subsequently activates protein kinase B (AKT) and causes upregulation of mammalian target of the rapamycin (mTOR) pathway $(10,11)$. PI $(3,4,5) \mathrm{P} 3$ in turn recruits BTK, PLC $\gamma 2$, and 3-phosphoinositide-dependent protein kinase 1 (PDK1) $(10,12)$. The pathways of the BCR/BTK signaling cascade are depicted in Fig. 1.

BTK was first revealed to be defective in the primary immunodeficiency X-linked agammaglobulinemia (XLA), which was initially described by Dr Ogden Carr Bruton in $1952(13,14)$. It is encoded by the XLA gene that is located on chromosome Xq21.3-22 and has a length of $37.5 \mathrm{~kb}(15,16)$. BTK is a non-receptor tyrosine kinase that belongs to the TEC family kinases (TFKs), which has five members (BTK, TEC, ITK, BMX and RLK/TXK) (17,18). BTK carries a conserved cysteine residue adjacent to an ATP-binding site, which is critical for inhibition by tyrosine kinase inhibitors $(17,19)$.
BTK has five domains: Pleckstrin homology (PH), Tec homology (TH), two Src homology domains (SH2 and SH3), and tyrosine kinase or Src homology 1 domain (TK or SH1, respectively) $(18,20)$. The expression of BTK is restricted to B lymphocytes, myeloid cells, erythroid cells, platelets, mast cells, macrophages, natural killer (NK) cells and myeloidderived suppressor cells (20-23). BTK is crucial for B-cell development, function of mature B cells, proliferation and survival of B-cells $(20,24)$. Constitutive-activation or mutation of the BTK pathways has been implicated in maintaining the malignant phenotype in a wide variety of B-cell malignancies, such as CLL, MCL and WM (25-27), and acute lymphoblastic leukemia (ALL) (28). BTK has been recognized as a therapy target for B-cell malignancies $(4,29)$.

Ibrutinib (formerly referred to as PCI-32765) is a first-in-class, orally bioavailable, small-molecule covalent inhibitor of BTK, which selectively and irreversibly inhibits BTK $(19,26,30)$. Ibrutinib selectively binds to the cysteine residue at position 481 (Cys-481) in the allosteric inhibitory segment of BTK (TK/SH1 domain), which blocks adenosine triphosphate (ATP) from binding, thereby preventing Btk phosphorylation and activation (19). The domain structure of BTK, the $\mathrm{C} 481$ binding site of ibrutinib and the chemical structure of ibrutinib are presented in Fig. 2. As a small-molecule inhibitor, kinase selectivity is a factor important for the efficacy and safety of ibrutinib. However, other kinases also have a cysteine residue in the ATP-binding site, such as TFK members, EGFR family kinases, BLK and JAK3 (31). Therefore, this on-target or off-target effect of ibrutinib may be used in other diseases or may cause adverse events (AEs). Recently, ibrutinib has also been used as a novel anticancer drug for several solid tumors and hematological malignancies, such as breast, ovarian, gastric and lung cancer, glioma, glioblastoma, $\mathrm{CD} 117^{+}$acute myeloid leukemia and $\mathrm{BCR}^{+}$ALL (32-39). 
Table I. Commonly used CPY3A4 inhibitors and inducers with ibrutinib.

Drug classification

Drugs

Strong CYP3A4 inhibitors

Antifungal drugs

Antibiotics

Antivirals

Antidepressants

Others

Moderate CYP3A4 inhibitors

Anti-arrhythmic drugs

Antifungal drugs

Antibiotics

Antivirals

Anti-emetics

Antineoplastic agents

Ketoconazole, voriconazole, posaconazole

Clarithromycin, telithromycin

Indinavir, nelfinavir, ritonavir, saquinavir

Nefazodone

Cobicistat, buprenorphine/naloxone

Mild CYP3A4 inhibitors

Antibiotics

Psychotropic drugs

Other

Amiodarone, diltiazem, verapamil, dronedarone

Fluconazole, itraconazole

Erythromycin, ciprofloxacin

Amprenavir, atazanavir, darunavir, fosamprenavir

Aprepitant

Crizotinib, imatinib

Strong CYP3A4 inducers

Antituberculosis drugs

Azithromycin

Fluvoxamine

Grapefruit juice, Seville oranges

Psychotropic drugs

Rifampin

Carbamazepine, phenytoin

Moderate CYP3A4 inducers

Anti-HIV drugs

Efavirenz

Others

St John's wort

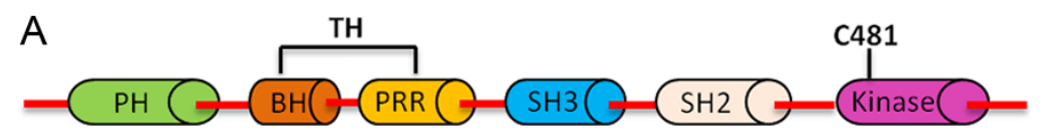

B

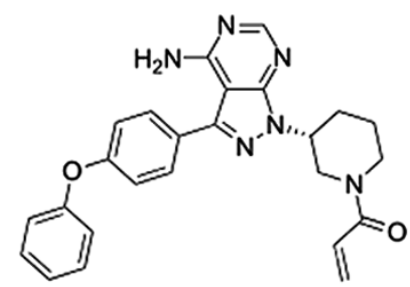

Figure 2. Structure of BTK, the C481 binding site of ibrutinib and the chemical structure of ibrutinib. (A) Domain structure of BTK and the C481 binding site of ibrutinib. (B) Chemical structure of ibrutinib. PH, pleckstrin homology; TH, TEC homology; BH, BTK homology; BTK, Bruton's tyrosine kinase; PRR, proline rich domain; SH2/SH3, SRC homology domains 2 and 3; kinase, tyrosine kinase domain or Src homology 1 domain.

\section{Drug-drug interactions (DDIs)}

Ibrutinib is primarily metabolized in the liver and is eliminated predominantly by cytochrome P450 enzyme 3A4 (CYP3A4) and less by CYP2D6 $(40,41)$. Caution must be exercised regarding the co-administration of ibrutinib with strong or moderate CYP3A4 inhibitors and inducers. Recently, in an analysis of 118 ibrutinib-treated patients with CLL, 75 patients (64\%) were on medications that could increase ibrutinib toxicity and $4(3 \%)$ were receiving drugs that could decrease ibrutinib efficacy (42). A previous study revealed that ketoconazole (a strong CYP3A4 inhibitor) increased the ibrutinib area under the curve (AUC) by 24-fold, while rifampin (a strong CYP3A4 inducer) decreased the ibrutinib AUC by 10-fold (41). Thus, co-administration of ibrutinib with CYP3A4 inhibitors or inducers should be avoided. If co-administration of strong CYP3A4 inhibitors or inducers is necessary, ibrutinib dosage modifications may be required. The CPY3A4 inhibitors and inducers commonly used with ibrutinib are summarized in Table I.

There is in vitro evidence to demostrate that ibrutinib inhibits $\mathrm{P}$-glycoprotein (P-gp) and breast cancer resistance protein (BCRP), although it is not a $\mathrm{P}$-gp or BCRP substrate (43). To minimize the risk of interactions, it is recom- 
mended that co-administration of ibrutinib and P-gp or BCRP substrates with a narrow therapeutic range should occur at least $6 \mathrm{~h}$ before or after ibrutinib (44). In addition, ibrutinib has a $\mathrm{pH}$-dependent solubility, with lower solubility at higher $\mathrm{pH}$. Although, co-administration of ibrutinib with omeprazole leads to the lower $\mathrm{C}_{\max }$ of ibrutinib, medicinal products that increase gastric $\mathrm{pH}$ have been used without restrictions in clinical trials (44).

\section{Application of ibrutinib in CLL/SLL}

A series of in vitro and mouse xenograft model preclinical studies have investigated the activity of ibrutinib against CLL (45-47).

Treatment-nä̈ve (TN) CLL/SLL. In an open-label phase 1b/2 trial (NCT01105247 and PCYC-1102) (48), previously untreated CLL/SLL patients who required therapy and were aged at least 65 years were enrolled. A total of 15 patients (48\%) had unmutated immunoglobulin heavy-chain variable region (IGHV), 2 (6\%) had del(17p13.1), 1 (3\%) had del(11q22.3), 17 (55\%) had del(13q14), and 8 (26\%) had trisomy 12 . The patients received 28-day cycles of oncedaily ibrutinib $420 \mathrm{mg}(\mathrm{n}=27)$ or $840 \mathrm{mg}(\mathrm{n}=4)$. The primary endpoint was safety and the severity of AEs for all patients. Toxicity (such as diarrhea, nausea and fatigue) was mainly of mild-to-moderate severity (grade 1-2). A total of $3(10 \%)$ patients developed grade 3 infections, 1 patient developed grade 3 neutropenia, and 1 developed grade 4 thrombocytopenia. The median time to initial response, best response and complete response (CR) was 1.9, 5.9 and 12.4 months, respectively. After a median follow-up of 22.1 months, 22 (71\%) patients achieved an objective response (OR), and 4 patients (13\%) had a CR. For all 31 patients at 24 months, the KaplanMeier estimate of progression-free survival (PFS) was $96.3 \%$ and the overall survival (OS) was $96.6 \%$. This phase $1 \mathrm{~b} / 2$ trial suggested that ibrutinib was well-tolerated and effective in a previously untreated population of elderly patients with CLL/SLL (48).

RESONATE-2 was an international, open-label, randomized phase 3 trial that evaluated the efficacy of ibrutinib (at a dose of $420 \mathrm{mg}$ once daily) and chlorambucil in previously untreated patients with CLL or SLL aged $\geq 65$ years and without chromosome 17p13.1 deletion (49). Of the patients, $70 \%(189 / 269)$ were aged at least 70 years, 45\% (122/269) had advanced-stage disease (Rai stage III or IV), and 20\% (54/269) had chromosome 11q22.3 deletion. The primary endpoint was PFS. At a median follow-up of 18.4 months, ibrutinib resulted in a significantly longer PFS compared with chlorambucil (median, not reached vs. 18.9 months, respectively) and resulted in a reduction of $84 \%$ in the risk of progression or death (hazard ratio $=0.16 ; \mathrm{P}<0.001$ ). At 18 months, the PFS was $90 \%$ in the ibrutinib group and $52 \%$ in the chlorambucil group. The 2-year OS rate in the ibrutinib group and chlorambucil groups was 98 and $85 \%$, respectively. The overall response rate $(\mathrm{ORR})$ was 86 vs. $35 \%(\mathrm{P}<0.001)$ in the ibrutinib and chlorambucil groups, respectively. Approximately $20 \%$ of the patients in the ibrutinib group suffered from AEs of any grade: 4 patients $(3 \%)$ in the ibrutinib group had grade 3 hemorrhage and $1(1 \%)$ had grade 4 hemorrhage (49).
Recently, a randomized phase 3 study (NCT02048813) on ibrutinib-based therapy compared with standard fludarabine/ cyclophosphamide/rituximab (FCR) chemoimmunotherapy (CIT) in treatment-naïve patients with CLL aged $<70$ years and without deletion $17 \mathrm{p}$ - was reported (50). The study revealed that the ibrutinib with rituximab (IR) group was superior to the FCR group independently of age, sex, performance status, disease stage or the presence/absence of del11q23, with fewer grade 3 and 4 treatment-related AEs (58 vs. $72 \%$, respectively). IR was also superior to FCR for IGHV unmutated but not IGHV mutated patients. Another phase 3 trial (NCT01886872) enrolled 547 untreated CLL patients aged $\geq 65$ years to evaluate the efficacy of ibrutinib-based therapy compared with CIT (51). The 2-year PFS was $74 \%$ with bendamustine plus rituximab (BR), $87 \%$ with ibrutinib alone and $88 \%$ with ibrutinib plus rituximab (IR). There was no significant difference in OS among the three treatment groups with a median follow-up of 38 months. The rate of grade $\geq 3$ hematological AEs was $61 \%$ in the BR group, $41 \%$ in the ibrutinib group and $39 \%$ in the IR group. The grade $\geq 3$ non-hematological AEs were $63 \%$ in the BR group, $74 \%$ in the ibrutinib group and $74 \%$ in the IR group (51).

iLLUMINATE (NCT02264574) is a multicentre, randomized, open-label, phase 3 trial comparing the efficacy of the combination of ibrutinib plus obinutuzumab (IO) with chlorambucil plus obinutuzumab (CO) (52). A total of 229 patients were enrolled (aged $\geq 65$ years or $<65$ years) with previously untreated CLL/SLL (52). The estimated 30-month PFS was $79 \%$ in the IO group and $31 \%$ in the CO group. The grade 3-4 AEs in both groups were neutropenia and thrombocytopenia. Serious AEs occurred in 65 out of 113 patients $(58 \%)$ treated with IO and in 40 out of 115 patients (35\%) treated with CO.

Relapsed or refractory CLL/SLL. In a multi-institutional phase 1 dose-escalating study, two dosing schedules of ibrutinib were analyzed in patients with relapsed or refractory CLL/SLL (R/R CLL/SLL) and other B-cell malignancies (FL, MCL, MZL, DLBCL and WM) (53). A total of 56 patients received ibrutinib at doses of $1.25(n=7), 2.5(n=9), 5.0(n=6)$, $8.3(\mathrm{n}=8)$, or $12.5(\mathrm{n}=7) \mathrm{mg} / \mathrm{kg} /$ day on a 28 -day on/7-day off schedule (35-day cycle), or continuous dosing of $8.3 \mathrm{mg} / \mathrm{kg} /$ day or $560 \mathrm{mg} /$ day until development of progressive disease (PD) or unacceptable toxicity. The results favored $12.5 \mathrm{mg} / \mathrm{kg} /$ day without reaching the maximum tolerated dose (MTD). The majority of AEs were grade 1 and 2 and self-limited. In the 50 patients evaluated for response, the objective response rate was $60 \%$, including a CR rate of $16 \%$. The median PFS in all patients was 13.6 months. Another phase $1 \mathrm{~b} / 2$ trial (NCT01105247, PCYC-1102) assessed the safety, efficacy, pharmacokinetics, and pharmacodynamics of ibrutinib in patients with R/R CLL or SLL (54). A total of 85 patients, $65 \%$ of whom were considered to have advanced-stage disease, were stratified into two treatment groups of once-daily ibrutinib $420 \mathrm{mg}(\mathrm{n}=51)$ or $840 \mathrm{mg}(\mathrm{n}=34)$ until development of PD or unacceptable toxicity. There was no difference in the time to peak ibrutinib concentration in the blood of the two groups. Toxic effects included transient diarrhea, fatigue and upper respiratory tract infection, which were predominantly grade 1 or 2 , without the need for treatment suspension. A total of 2 patients in the 420-mg cohort (4\%) and 4 patients 
in the 840-mg cohort (12\%) suffered from SAEs that led to discontinuation of treatment. The overall response rate was the same in the two groups (71\%). An additional 20 and $15 \%$ of the patients in the 420 and $840 \mathrm{mg}$ cohorts, respectively, had a partial response (PR), with lymphocytosis. The response was irrelevant to the clinical and genomic risk factors present pretreatment, such as advanced-stage disease, number of previous treatments and the $17 \mathrm{p} 13.1$ deletion. At 26 months, the PFS was $75 \%$ and the OS was $83 \%$ (54).

In the first randomized phase 3 RESONATE study (PCYC-1112), 391 elderly patients with R/R CLL/SLL were randomized to receive either ibrutinib (at a dose of $420 \mathrm{mg}$ once daily) or ofatumumab (55). The primary endpoint was PFS. During a median follow-up of 9.4 months, the median PFS was not reached in the ibrutinib cohort compared with 8.1 months in the ofatumumab cohort. Ibrutinib also significantly improved OS (1-year OS rate $90 \%$ vs. $81 \%$, respectively) and overall response rate (42.6\% vs. $4.1 \%$, respectively) (55).

In 2015, the 3-year follow-up data from PCYC-1102 and the ongoing long-term extension study PCYC-1103 in 132 patients (85 patients with R/R CLL/SLL, 31 patients with $\mathrm{TN}$, and 16 patients with $\geq 2$ prior therapies) revealed that prolonged treatment with ibrutinib ameliorated the quality of response over time, with durable remissions and acceptable toxicity (56). In 2017, the authors reported the safety and efficacy outcomes with continued follow-up (up to 44 months) of patients in the phase $1 \mathrm{~b} / 2$ study (PCYC-1102) and extension study (PCYC-1103) receiving ibrutinib $420 \mathrm{mg}$ once-daily until progression (57). A total of 94 CLL/SLL patients (27 with $\mathrm{TN}$ and 67 with R/R) were treated with ibrutinib. The best overall response was $85 \%$ in TN patients and $94 \%$ in $\mathrm{R} / \mathrm{R}$ patients. The median PFS was not reached in either group and the 30-month PFS rate was 96 and $76 \%$ for TN and R/R patients, respectively (57). Recently, O'Brien et al reported 5-year follow-up data from the PCYC-1102 and PCYC-1103 studies on ibrutinib monotherapy for $\mathrm{TN}(\mathrm{n}=31)$ and $\mathrm{R} / \mathrm{R}$ $(n=101)$ CLL/SLL (58). With a 5-year follow-up, ibrutinib yielded an overall response rate of $89 \%$, with CR of $29 \%$ in TN and $10 \%$ in R/R patients. The 5-year PFS rate was 92 and $44 \%$ in $\mathrm{TN}$ and $\mathrm{R} / \mathrm{R}$ patients, respectively. The median PFS in $\mathrm{R} / \mathrm{R}$ patients was 51 months. Subgroup analysis demonstrated that the median PFS in those with del(11q), del(17p), and unmutated IGHV was 51, 26 and 43 months, respectively. A total of $45 \%$ of $\mathrm{TN}$ patients and $72 \%$ of $\mathrm{R} / \mathrm{R}$ patients discontinued treatment, with the most common reasons being AEs (19\% TN and $21 \% \mathrm{R} / \mathrm{R})$ and disease progression (6\% $\mathrm{TN}$ and $33 \% \mathrm{R} / \mathrm{R})$. The most common grade $\geq 3 \mathrm{AEs}$ in $\mathrm{TN}$ and $\mathrm{R} / \mathrm{R}$ patients were hypertension (32\% TN and 25\% R/R), pneumonia (10\% TN and $27 \% \mathrm{R} / \mathrm{R})$, neutropenia ( $3 \% \mathrm{TN}$ and $21 \% \mathrm{R} / \mathrm{R})$, thrombocytopenia ( $3 \% \mathrm{TN}$ and $11 \% \mathrm{R} / \mathrm{R})$, and atrial fibrillation (AF; $6 \% \mathrm{TN}$ and $9 \% \mathrm{R} / \mathrm{R})(58)$.

CLL patients with $17 \mathrm{p}$ deletion (del17p) have poor responses and survival after CIT. A phase 2, single-arm trial of ibrutinib for previously untreated and R/R CLL patients with TP53 aberrations demonstrated that $32(97 \%)$ of 33 previously untreated patients and $12(80 \%)$ of $15 \mathrm{R} / \mathrm{R}$ CLL patients achieved an objective response (59). The study revealed that the activity and safety profile of ibrutinib in CLL with TP53 aberrations are encouraging. Recently, the 5-year follow-up of this study was reported (60). The overall response rate at 6 months was
95.8\% (CR, 29.2\%) for the TP53 cohort and 93.9\% (CR, 27.3\%) for the elderly cohort. The 5-year PFS was $74.4 \%$ and $19.4 \%$ in TN-CLL and RR-CLL in the TP53 cohort, respectively, and the OS was 85.3 vs. $53.7 \%$, respectively. The 5-year PFS and OS in RR-CLL were 64.8 and $71.6 \%$ in the elderly cohort, respectively. AF occurred in 18 (20.9\%) patients, and there was no reported serious bleeding. Another phase 2, openlabel, multicentre, single-arm study (RESONATE-17) with $\mathrm{R} / \mathrm{R}$ del17p CLL/SLL patients received ibrutinib $420 \mathrm{mg} /$ day until PD or unacceptable toxicity (61). A total of $83 \%$ patients (119/144) had an overall response according to investigator assessment. The 2-year PFS and OS were $63 \%$ and $75 \%$, respectively. Grade 3-4 bleeding occurred in 13 patients. Forty-three patients suffered from grade 3 or worse infections, including 19 patients with pneumonia (61). Recently, a pooled analysis from 3 clinical trials (PCYC-1102/1103, PCYC1112 and PCYC-1117) evaluated 230 R/R CLL patients with del17p (62). With a median follow-up of 28 months, the overall response rate was $85 \%$. The estimated PFS rate at 12,24 and 30 months was 80,65 and $57 \%$, respectively. The estimated OS rate at 12,24 and 30 months was 85,77 and $69 \%$, respectively. Subgroup analysis revealed that the overall response rate was the same for patients with and without complex karyotype (86\% for both). However, patients with complex karyotype had a worse estimated median PFS (26 vs. 52 months) and OS (32 months vs. not reached). Grade $\geq 3$ AEs occurring in $\geq 5 \%$ of patients included neutropenia, pneumonia, hypertension, thrombocytopenia, anemia and urinary tract infection.

All these clinical trials suggested that ibrutinib is well tolerated and effective in the treatment of newly diagnosed and $\mathrm{R} / \mathrm{R}$ CLL, including patients with del17p.

Real-world studies. In a real-world study of ibrutinib in $\mathrm{R} / \mathrm{R}$ CLL patients (65\% with del17p/TP53 mutations) from the Swedish Chronic Lymphocytic Leukemia Group, the response rate was $84 \%$ and the PFS was $77 \%$ at a median follow-up of 10.2 months (63). Patients with del17p/TP53 mutations had shorter PFS and OS (63).

The data on practice patterns following ibrutinib discontinuation are limited. Mato et al conducted a multicenter, retrospective analysis on 178 patients with CLL (ibrutinib $\mathrm{n}=143$; idelalisib $\mathrm{n}=35$ ) who discontinued BTK inhibitor therapy (64). The most common reasons for BTK inhibitor discontinuation were toxicity $(51 \%)$, disease progression (29\%), and Richter transformation (RT) (8\%). The reported overall response rate was $58 \%(15 \% \mathrm{CR} ; 22 \%$ stable disease and $20 \%$ partial response) in the ibrutinib cohort. The median PFS and OS for the entire cohort $(n=178)$ from BTK inhibitor initiation were 10.5 and 29 months, respectively. The median PFS in BTK inhibitor-intolerant patients treated with an alternative BTK inhibitor was not reached vs. 7 months for patients with CLL progression on the first BTK inhibitor, and who were subsequently treated with an alternative BTK inhibitor. Therefore, BTK inhibitor-intolerant patients without CLL progression, may be successfully treated with different BTK inhibitors (64).

The real-world results of ibrutinib in R/R CLL patients with poor prognosis $(92.9 \%$ of patients had advanced Binet stage B/C, 45.1\% had del17p and/or TP53 mutation, and 54.2\% had at least one significant comorbidity) previously treated 
with FCR, R-bendamustine, chlorambucil \pm steroids $\pm \mathrm{R}$, ofatumumab, alemtuzumab \pm steroids, R-CHOP and transplantation in France revealed that the best overall response rate was $88.5 \%$ (65). The authors also evaluated the safety of ibrutinib, with $73.4 \%$ of patients experiencing $\geq 1$ AEs of mild-to-moderate severity and $33.2 \%$ experiencing $\geq 1$ SAEs, confirming the good safety and efficacy of ibrutinib in a realworld setting. In the largest real-world experience of novel agents in CLL, ibrutinib appears to be superior to idelalisib as first kinase inhibitors (KI) (66).

Recently, the largest named patient program (NPP), which was compared with the phase 3 RESONATE (PCYC-1112) study, was conducted across 30 countries and 2,908 patients with R/R CLL were enrolled (67). The estimated proportion of patients on treatment at 12 months was 77.3 and $81.5 \%$ in the NPP and RESONATE study, respectively (67). In the NPP, 332 patients (11.4\%) discontinued ibrutinib (mostly due to death, $\mathrm{n}=123$; PD, $\mathrm{n}=55$; AEs, $\mathrm{n}=50$ ), whereas in RESONATE, the discontinuation rate due to AEs was $4 \%$ of the patients (67). In a subset of the UK/Ireland NPP patients $(\mathrm{n}=315)$, the 1-year OS rate was $83.8 \%$, with $73.7 \%$ of patients still receiving therapy at 1 year (68). Using univariate analysis, the NPP analysis by the UK CLL Forum demonstrated that OS and discontinuationfree survival (DFS) were not associated with the number of prior lines of therapy or $17 \mathrm{p}$ deletion, while, with multivariate analysis revealed that older patients with del17p had inferior survival when treated with ibrutinib (68). With multivariate analysis in the international NPP study, time-on-treatment was significantly longer for patients who were younger (67). This NPP study suggested that ibrutinib is effective and well-tolerated in the real-world setting, with similar time-on-treatment to the RESONATE (PCYC-1112) study (67).

What is the relationship of dose intensity (DI) and response? Barr et al evaluated the effect of ibrutinib dose adherence on patient outcomes in the phase 3 RESONATE trial (69). This study demonstrated that patients with higher ibrutinib DI experienced longer median PFS, independent of del17p or TP53 mutation. Patients missing $\geq 8$ consecutive days of ibrutinib had a shorter median PFS vs. those missing $<8$ days (10.9 months vs. not reached).

Combination therapy of ibrutinib with other agents. Despite the promising therapeutic efficacy of ibrutinib in CLL, CR is infrequent, and acquired resistance to ibrutinib has been reported. Combination therapy may increase the rate of CR and overcome resistance to ibrutinib.

An in vitro study reporting that ibrutinib can interfere with the cell-mediated antitumor activities of therapeutic CD20 antibodies provided grounds for combination therapy (70). Another in vitro and mouse model study demonstrated that the XPO1 inhibitor selinexor exerted a synergistic effect with ibrutinib in primary CLL cells and increased OS compared with ibrutinib alone (71).

The results of previous clinical studies reported a good response with good tolerability when ibrutinib was used in combination with chemoimmunotherapy, anti-CD20 antibodies (rituximab, ofatumumab, obinutuzumab and TG-1101), or Bcl-2 inhibitors (ABT-199) (72-78).

A single-arm, phase 2 study evaluated the safety and activity of ibrutinib plus rituximab for patients with high-risk
CLL (73). The 18-month PFS in all patients was 78.0\%, whereas in those with a del17p or TP53 mutation, it was $72.4 \%$. The 18-month OS in all patients was $83.8 \%$, whereas in those with del17p or TP53 mutation, it was $78.4 \%$. Toxicity was mainly mild to moderate in severity (grade 1-2), with 5 patients (13\%) experiencing grade 3 infections, and there were no grade 4 or 5 infections (73). Another phase $1 b / 2$ study assessed the safety and activity of ibrutinib in combination with the anti-CD20 antibody ofatumumab in R/R CLL (including prolymphocytic leukemia, or Richter's transformation) (74). A total of 71 patients were treated, including 66 CLL/SLL patients. The trial was divided into 3 groups: Ibrutinib lead-in (group 1, $n=27$ ), concurrent start (group 2, $n=20$ ), or ofatumumab lead-in (group 3, n=24). Of the 71 patients, $68(96 \%)$ were evaluable for response. The overall response rates among patients with CLL/SLL patients were $100 \%, 78.9 \%$ and $70.8 \%$ in groups 1,2 and 3 , respectively. The median PFS had not yet been reached at a median time on study of 12.5 months. The estimated 12-month PFS was $88.7 \%, 85 \%$ and $75 \%$, in groups 1,2 and 3 , respectively. The estimated 12 -month OS was $92.3 \%, 85 \%$ and $87.5 \%$ in groups 1,2 and 3, respectively (74). Ublituximab (TG-1101), a novel glycoengineered anti-CD20 antibody, was also evaluated in combination with ibrutinib in R/R CLL in a phase 2 study (76). Combination therapy resulted in an overall response rate of $88 \%$ at 6 months, with 2 subjects (5\%) achieving a CR and 34 subjects (83\%) a PR. In the high-risk CLL population $(\mathrm{n}=20)$, the overall response rates were $95 \%$, with $10 \% \mathrm{CR}$ and $85 \%$ PR. The most common AEs were infusion-related reaction (IRR), diarrhea, fatigue, nausea and rash (76). All these clinical trials suggested that ibrutinib in combination with anti-CD20 antibodies can be used as a treatment option for CLL/SLL.

A phase $1 \mathrm{~b}$ clinical trial (PCYC-1108) evaluated the safety and efficacy of ibrutinib in combination with CIT in patients with R/R CLL (78). The study enrolled patients into 2 parallel cohorts, bendamustine, rituximab plus ibrutinib (BR-ibrutinib, $\mathrm{n}=30$ ) and fludarabine, cyclophosphamide, rituximab plus ibrutinib (FCR-ibrutinib, n=3). CIT was up to 6 cycles and ibrutinib was administered daily at a dose of $420 \mathrm{mg}$ after CIT infusions until disease progression or unacceptable toxicity. With a median treatment duration of 15.7 months, the estimated 6- and 12-month PFS of the BR-ibrutinib cohort was $93.1 \%$ and $85.9 \%$, respectively. The overall response rate with BR-ibrutinib was $93.3 \%$, and with FCR-ibrutinib it was $100 \%$. Safety was as expected with either CIT or single-agent ibrutinib, with the majority of treatment-related AEs being grade 1 or 2. A total of 6 SAEs in the BR-ibrutinib cohort (1 event of tumorlysis, 2 events of cellulitis, 1 event of dehydration, 2 events of febrile neutropenia) and $1 \mathrm{SAE}$ in the FCR-ibrutinib cohort (gastrointestinal bleeding) were reported. This PCYC1108 study demonstrated that ibrutinib may enhance CIT efficacy without additive toxicities (78).

A randomized, double-blind, placebo-controlled, phase 3 study (HELIOS) evaluated ibrutinib in combination with bendamustine plus rituximab compared with placebo, bendamustine, and rituximab for CLL/SLL patients who had received one or more prior systemic therapies (79). The investigator-assessed overall response rates were 86\% (249/289) of patients in the ibrutinib group compared with 69\% (199/289) of patients in the placebo group. At a median follow-up of 
17 months, the PFS was significantly improved (not reached in the ibrutinib group vs. 13.3 months in the placebo group). PFS at 18 months was $79 \%$ in the ibrutinib group and $24 \%$ in the placebo group (79). There was no statistically significant difference in OS between the two groups. However, after adjusting for crossover (90 out of 289 patients from the placebo group crossed over to receive ibrutinib after disease progression), patients in the ibrutinib group had a significantly better OS compared with those in the placebo group (79). The frequency of infections was similar between the ibrutinib and placebo groups (all-grade: 70\% vs. 70\%). Major hemorrhage was more frequent in the ibrutinib group compared with the placebo group (4\% vs. $2 \%$, respectively) (79).

A phase 1 trial evaluated the safety and efficacy of the triplet combination of ibrutinib with a novel anti-CD20 mAb (ublituximab) and a PI3Kס inhibitor (TGR-1202) in patients with R/R B-cell malignancies (80). A total of 38 patients were enrolled: 20 CLL/SLL, 6 FL, 6 DLBCL, 4 MCL and 2 MZL cases. The overall response rates of 36 evaluable patients were CLL/SLL 100\% (CR 3, PR 16), MCL 100\% (CR 1, PR 3), FL/MZL 86\% (CR 2, PR 4) and DLBCL 17\% (CR 0, PR 1).

Recently, a phase 1 study of lenalidomide and ibrutinib in combination with rituximab in R/R CLL was reported (81). The study demonstrated that the overall response rate was $67 \%$ and the combination of ibrutinib, lenalidomide and rituximab did not appear to be more effective compared with the rituximablenalidomide doublet or single-agent ibrutinib with sustained grade 4 neutropenia (81). Table II summarizes the completed clinical trials of ibrutinib in CLL/SLL malignancies.

\section{Ibrutinib resistance and management}

As described above, ibrutinib alone or as part of combination therapies has achieved remarkable responses in treatmentnaïve patients or those with R/R B-cell malignancies. However, several patients developed PD during ibrutinib treatment. Recently, Hershkovitz-Rokah et al reviewed 5 published studies including 539 patients in total (82). They found that primary resistance ranged from $10.2 \%$ to $35 \%$ and acquired resistance ranged from $17.5 \%$ to $54 \%$ (82).

A 49-year-old woman enrolled in a phase 1 study of ibrutinib exhibited a rapidly rising lymphocyte count and progressive lymphadenopathy at month 21 (53). RNA sequencing revealed a thymidine-to-adenine mutation at nucleotide 1634 of the BTK complementary DNA (83). This mutation leads to a substitution of serine for cysteine at residue 481 (C481S), which disrupts covalent binding of ibrutinib to the sulfhydryl group of C481 of BTK in the active site and leads to a loss of inhibition of BTK enzymatic activity (83).

Another study demonstrated that BTKCys481 and PLC $\gamma 2$ mutations appear early and have the potential to be used as biomarkers for future relapse in CLL patients (84). Ahn et al reported a prognostic scoring system in CLL patients treated with single-agent ibrutinib on an investigator-initiated phase 2 trial (85). With median follow-up of 34 months, $17.9 \%$ patients (15/84) progressed. Most cases of ibrutinib-resistant CLL were due to mutations in BTK and/or PLCG2. Using high-sensitivity testing could detect mutations up to 15 months before manifestation of clinical progression (85). Long-term follow-up results and validation of the prognostic models in a large inde- pendent cohort of patients with CLL was reported (86). They determined that with BTK and/or PLCG2 mutations heralded ibrutinib resistance.

A study that evaluated prolonged use of ibrutinib in a reallife setting from the French Innovative Leukemia Organization (FILO) Group was reported in an ASH meeting (87). This real-life study also highlighted the onset of BTK and PLC $\gamma 2$ mutations before any evidence of disease progression.

Except BTK, PLC $\gamma 2$ and CARD11 mutation-mediated ibrutinib resistance, nurse-like cells (NLC) in the tumor microenvironment (TME) may play a role in ibrutinib resistance (88). It has been demonstrated that ibrutinib may impair the phagocytosis of rituximab-coated leukemic cells from CLL patients by human macrophages and antagonize rituximab-dependent NK cell-mediated cytotoxicity $(89,90)$. These results suggested that the sequential administration, but not the concurrent treatment, with these agents may enhance their antitumor activity.

A preclinical study demonstrated that HSP90 inhibitors can overcome ibrutinib resistance in vitro and in vivo by the degradation of both BTK and IКB kinase, with downstream loss of MAPK and non-classical NF- $\kappa$ B signaling (91). Srour et al reported that a chemotherapy-free combination that includes dexamethasone, rituximab, lenalidomide and bortezomib (DR2IVE) can overcome resistance in heavily treated ibrutinib-resistant MCL patients, achieving an optimal response (92). Other resistance mechanisms and how to overcome ibrutinib resistance was summarized in a review by Hershkovitz-Rokah (82) and is investigated in ongoing clinical trials (Clinical trial information: NCT02912754, NCT03513562, NCT02973399, NCT02914327).

\section{Side effects and management}

$A F$. One study demonstrated that the incidence of AF was $\sim 5 \%$ in the ibrutinib group in CLL (55). Another study including 4 RCTs (RESONATE, RESONATE-2, HELIOS and RAY) reported that the AF incidence was $6.5 \%$ for the ibrutinib group at 16.6 months and $10.4 \%$ at 36 months of follow-up (93). Univariate analyses identified prior history of AF, ibrutinib exposure, age $\geq 65$ years, hypertension, and hyperlipidemia as significant risk factors for developing AF. However, the effect of prior coronary artery disease, valvular heart disease and diabetes were not identified as significant risk factors. Multivariate analyses revealed that prior history of AF, ibrutinib exposure and age $\geq 65$ years were independent predictors of AF. Gustine et al identified 112 patients with WM and revealed that $12(10.7 \%)$ patients were diagnosed with AF, of whom $6(50 \%)$ had a prior history of AF (94). The median time to AF was 3.9 months vs. 33.4 months in patients with a prior history of AF compared with patients without a history of AF, respectively (94). The incidence may increase with the duration of the medication (up to $16 \%$ in longer-term followup) (95). A systematic review and meta-analysis suggested that ibrutinib consistently increases the risk of AF compared with control. The authors advised that patient exposure to ibrutinib should be closely monitored (96). Although BTK and TEC protein kinases are expressed in cardiac tissue and inhibited by ibrutinib, the mechanism of AF remains elusive and requires further investigation. A preclinical mouse model suggested 


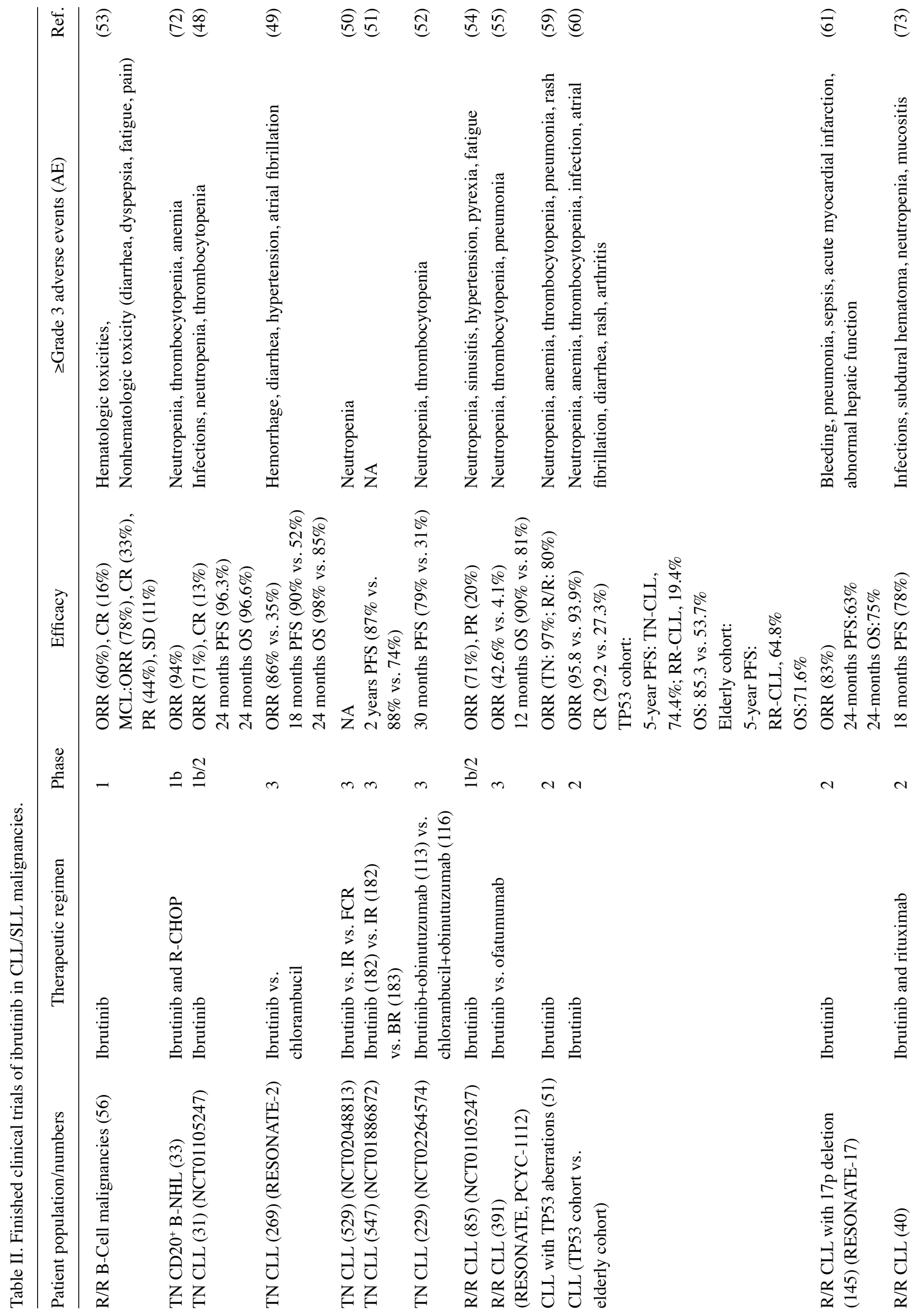


that ibrutinib-related AF may be mediated through inhibition of PI3K/Akt signaling (97).

In an international retrospective study, Thompson et al reported that median time to onset AF was 3.8 months. AF was persistent in $65 \%(35 / 56)$ cases despite treatment and ibrutinib was permanently discontinued in $46 \%(26 / 56)$ cases (98).

Since bleeding is another common side effect and several anticoagulants and anti-arrhythmic drugs (e.g. verapamil, amiodarone) interact with ibrutinib $(99,100)$, managing AF is particularly challenging due to the increased bleeding risk of anticoagulation for AF stroke prophylaxis. Wang et al reported that MCL patients who suffered from AF were controlled with $\beta$-blockers and/or antiarrhythmics (amiodarone, dronedarone), and 1 patient underwent ablation therapy. Half of the patients who suffered from AF were treated with anticoagulants (warfarin and low-dose heparin), and no patients discontinued therapy as a result of AF (101). Brown et al revealed that $49.0 \%$ (24/49) of the patients with $\mathrm{AF}$ in the ibrutinib group and $33.3 \%(4 / 12)$ in the comparator were managed without any interruption or modification of the study drug. Patients with ibrutinib dose interruption for $\geq 7$ days vs. those for $<7$ days exhibited no statistically significant difference in the 18-month PFS (93). Also in this study, the author summarized that $34.7 \%$ (17/49) of patients of the ibrutinib group who had an AF event were receiving antiplatelet medications and $8.2 \%(4 / 49)$ were taking an anticoagulant. The most commonly used antiplatelet and anticoagulant agents were aspirin and low-molecular-weight heparin, respectively (93). Most scholars advised avoiding P-glycoprotein substrates (e.g., digoxin) and CYP3A4 inhibitors (e.g., verapamil, amiodarone, diltiazem) to control the ibrutinib-related AF (IRAF) and propose deciding whether to prescribe anticoagulation according to the $\mathrm{CHA}_{2} \mathrm{DS}_{2}-\mathrm{VASc}$ (the risk of stroke) and HAS-BLED (the risk of bleeding) scoring methods to decide whether to give anticoagulation or not (102-104). If CHA2DS ${ }_{2}$-VASc $\leq$ HAS-BLED, there is no need to prescribe an anticoagulant agent and ibrutinib therapy may continue $(102,104)$. In a secondary analysis of data from the phase 2 PCYC-1102 study and phase 3 PCYC-1112 study, the use of antithrombotic agents was common, with $\geq 50 \%$ of patients on ibrutinib receiving an anticoagulant, antiplatelet, or a combination of both (105). Recently, Gribben et al provided detailed recommendations on how to prescribe anticoagulation (apixaban and dabigatran) and antiplatelet (aspirin and clopidogrel) therapy (106).

Bleeding. The other important AE is bleeding $(56,101)$. Studies demonstrated that ibrutinib selectively inhibits collagen and von Willebrand factor (vWF)-mediated platelet activation (107-109). The platelet function assay revealed impaired aggregation at baseline after ibrutinib treatment increased from 22/85 to 41/85 (108). Brown et al summarized 4 RCTs (RESONATE, RESONATE-2, HELIOS and RAY) and revealed that the incidence of bleeding events was $38.8 \%$ (293/756) and 17.2\% (129/749) in the ibrutinib group and comparator groups, respectively; the majority of events were grade 1 or 2 (91.5 and $88.3 \%$, respectively) (93). In a phase 3 trial enrolling 280 patients with R/R MCL (ibrutinib group: $\mathrm{n}=139$; temsirolimus group: $\mathrm{n}=141$ ), a major bleeding event 
was reported in $14(10 \%)$ patients in the ibrutinib group and in $9(6 \%)$ in the temsirolimus group (110). A systematic review confirmed an increased incidence of any-grade bleeding, with a 2.93 -fold increase in the ibrutinib group compared with the control group, with the risk of major bleeding also increased (111).

Several patients treated with ibrutinib have comorbidities such as cardiovascular disease, warranting antiplatelet or anticoagulant therapy for primary or secondary prevention. Based on the observation of occasional severe hemorrhage, including subdural hematoma and post-traumatic surgical hemorrhage, the safety issue of combination therapy with ibrutinib and antiplatelet/anticoagulant drugs was proposed, but the information on ibrutinib in combination with anticoagulant or antiplatelet treatment was not released $(101,112)$. At present, few data are available on the safety of concomitant ibrutinib with warfarin/ other vitamin $\mathrm{K}$ antagonist, as patients requiring anticoagulant therapy with warfarin/other vitamin $\mathrm{K}$ antagonist were excluded from subsequent trials $(55,73)$. In the HELIOS study, 6 out of 11 patients with major hemorrhage in the ibrutinib group were taking a concomitant anticoagulant or antiplatelet treatment (79). In the RESONATE study, the authors excluded patients requiring warfarin, but not those requiring other forms of anticoagulation. The major hemorrhage incidence was similar in the two study groups (2 patients in the ibrutinib group and 3 patients in the ofatumumab group), while bleeding-related AEs of any grade were more common in the ibrutinib group compared with the ofatumumab group (44\% vs. $12 \%$, respectively) (55). Data from the PCYC-1104-CA trial suggest that the combination of antiplatelet agents and ibrutinib increases the risk of bleeding (101). Another study revealed that grade $\geq 3$ bleeding occurred in $\sim 3 \%$ in patients without concomitant anticoagulant/antiplatelet therapy (105). A real-world study reported no increased incidence of bleeding in 19 patients who received concomitant low-molecular-weight heparin and 5 patients who received aspirin or clopidogrel (63). Similarly, in a report of patients on concomitant directly acting oral anticoagulant (DOAC) therapy, none of the 15 patients developed major bleeding (98). Experience with ibrutinib in combination with both antiplatelet and anticoagulant agents is limited. A meta-analysis demonstrated that dual antiplatelet therapy with aspirin and a P2Y12 antagonist (clopidogrel, prasugrel or ticagrelor) increases the risk of major bleeding by 40-50\% compared with single-agent antiplatelet therapy (113). Adding ibrutinib to dual antiplatelet therapy (DAPT) is likely to further increase this risk. Based on the available data, Shatzel et al reviewed patients taking ibrutinib with concomitant antiplatelet and anticoagulant agents; more information may be found in that review (114).

Bleeding events in patients receiving ibrutinib are usually mild, mostly grade 1 and 2 , and do not require dose modification/interruption. In the case of serious bleeding, platelet transfusion is recommended, regardless of the platelet count. Antifibrinolytic drugs, such as tranexamic acid, may be prescribed if bleeding persists after platelet transfusion. Additionally, in vitro studies demonstrated that platelet aggregation is fully restored within 5-7 days after ibrutinib cessation $(107,109)$. It was recommended that ibrutinib should be withheld for 3-7 days before and after any surgical or invasive procedures (112).
Infection. B-cell malignancies are characterized by immune dysregulation, with associated hypogammaglobulinemia and recurrent infections. Considering that ibrutinib plays important roles in both normal and malignant B lymphocytes, the effect of ibrutinib on infection risk and immunoglobulin levels in B-cell malignancies should be assessed. Apart from BTK, ibrutinib is also an irreversible inhibitor of interleukin2-inducible T-cell kinase (ITK), which plays an important role in inflammatory responses and T-cell maturation (115). Without ITK, CD4 ${ }^{+} \mathrm{T}$ cells do not effectively differentiate into Th2 effector cells and cannot elicit protective responses to pathogens, which increases the risk of severe and opportunistic infections, such as Candida species, Pneumocystis jirovecii, Epstein-Barr virus and varicella zoster virus (VZV) $(115,116)$. Byrd et al had revealed that the most common AEs of grade $\geq 3$ of ibrutinib included pneumonia (12\%) (54). O'Brien et al also reported that $\sim 10 \%$ of the patients developed grade 3 infections (48). Some case reports and retrospective cohort studies also demonstrated that ibrutinib was associated with serious pneumonia and opportunistic infections, such as pneumocystosis, aspergillosis, herpes simplex virus, VZV, cytomegalovirus, cryptococcal meningitis, candidiasis, fusarium and other invasive mold infections (117-119). A previous study demonstrated that 5 cases (5.2\%) of Pneumocystis jirovecii pneumonia (PJP) were identified in 96 patients with CLL treated with ibrutinib (120). Furthermore, the authors revealed that all patients had a CD4 T-cell count $>500 / \mu 1$ and $\mathrm{IgG}>500 \mathrm{mg} / \mathrm{dl}$ at the time of PJP, indicating that PJP may be linked to ibrutinib (120). Lionakis et al reported that $39 \%$ (7/18) patients with primary CNS lymphoma (PCNSL) who received ibrutinib combination therapy developed invasive aspergillosis (121). Diamantopoulos et al reported a 72-yearold man with stage IV MCL (122). After receiving ibrutinib for 5 months, he developed Staphylococcus aureus meningitis. A systematic review demonstrated that $\sim 56 \%$ of patients on single-agent ibrutinib and $52 \%$ of those on combination therapy developed infectious complications, and grade 3-4 infectious AEs occurred in 26 and 20\%, respectively (123). Aspergillus, VZV and Pneumocystis were the most common opportunistic pathogens (123). Recently, Varughese et al reviewed 378 patients with lymphoid malignancies, and revealed that 43 of the patients suffered from serious infection, of whom $37.2 \%$ (16/43) developed invasive fungal infections (IFIs) (124). Ghez et al reported the results of a retrospective survey in France, and identified 33 cases of IFIs in patients receiving ibrutinib alone or in combination (125). Most of IFIs occurred within a median of 3 months after starting ibrutinib. Invasive aspergillosis (IA) accounted for the majority of IFIs (27/33), including 40.7\% (11/27) with CNS localizations (125). Tuberculosis infection after ibrutinib should also be taken into consideration (126).

However, a different sensitivity of malignant and normal B cells to ibrutinib may potentially restore immune system function. Sun et al assessed humoral immunity and B-cell subsets in 86 patients with TN or R/R CLL who had received ibrutinib for at least 12 months (127). They, consistently with other researchers, found that there was a decrease in serum $\operatorname{IgG}$ and IgM levels and an increase in serum IgA level $(48,54,127)$. Yin et al noted elevated peripheral blood $\mathrm{CD}^{+}$and $\mathrm{CD} 8^{+} \mathrm{T}$-cell numbers and T-cell-related cytokine levels (128). Studies have 
also reported that the infection rate declined by more than $50 \%$ after 6 months of ibrutinib therapy $(56,127)$. This may be due to the partial reconstitution of humoral immunity and cellular immunity $(127,128)$.

Secondary primary malignancies (SPMs). Another less reported but important AE of ibrutinib are SPMs. The overall incidence of other malignancies was $5 \%$ in clinical trials, including skin cancers (4\%) and other carcinomas (1\%) (101).

Hepatitis $B$ virus $(H B V)$ reactivation. Certain therapies for hematological malignancies are associated with increased risk of HBV reactivation in previously infected patients $(129,130)$. De Jesus Ngoma et al reported the first case of HBV reactivation in an 80-year-old CLL patient receiving ibrutinib, suggesting that such treatment must be associated with $\mathrm{HBV}$ screening (131). In 2017, Herishanu et al reported a 79-yearold HBsAg-negative, anti-HBs- and anti-HBc-positive CLL patient who suffered from severe HBV reactivation 1 year after starting ibrutinib (132). However, Tedeschi et al revealed that $18 \%$ (7/38) of CLL patients were determined to be HbsAgnegative/anti-Hbc-positive with undetectable HBV DNA before starting ibrutinib (133). After a median follow-up of 25 months, none of the patients exhibited HBV reactivation, suggesting that any recommendation that prophylaxis during ibrutinib treatment should be administered to anti-Hbc-positive patients was not enough. Thus, further systematic studies are warranted to assess the risk of HBV reactivation during ibrutinib therapy to provide appropriate recommendations.

Other side-effects. In published studies, rash or pruritic rash occurs at a frequency of $13-27 \%$ with single-agent ibrutinib $(48,54,134)$. The combination therapy of ibrutinib with rituximab and lenalidomide is associated with a high incidence of all-grade rash, up to $82 \%$ (grade 3, 36\%) (135). Mannis et al reported the case of a 67-year-old man with del17p CLL who developed non-pruritic, edematous papules after 2 weeks of ibrutinib treatment, characterized by peripheral-to-central spread (136). Jensen et al reported the case of a 79-year-old man with WM who developed a painless, slightly pruritic rash starting from the groin and wrists and subsequently spreading to the trunk and extremities after 12 weeks of ibrutinib treatment (137).

Iberri et al defined the clinicopathological characteristics and management of patients with ibrutinib-associated rash (138). They observed two distinct rash subtypes: i) A non-palpable, largely asymptomatic petechial rash and ii) a palpable eruption characterized by pruritic, non-blanching, violaceous papules. Most non-palpable rashes were grade 1-2 and required no dose interruptions or delays of ibrutinib. Patients with palpable rash all received topical corticosteroids and oral antihistamines, with (grade 3) or without (grade 1-2) interruption of ibrutinib (138).

Neffendorf et alhad reported that an 80-year-old woman with CLL who had received ibrutinib had a 1-month history of deteriorating vision and bilateral cataracts (139). As tyrosine kinase receptors, such as EPHA2, are known to be key regulators in lens clarity and organization, the authors raised the possibility that a tyrosine kinase mechanism may be implicated in the cataracts. They also advised that old patients who receive ibrutinib should have baseline and repeated visual acuity testing, as well as ophthalmological assessment in case of visual deterioration (139). Wallace et al reported the case of a 78-year-old man with a history of MCL who experienced new-onset cardiomyopathy and ventricular tachycardia after 4 months of ibrutinib therapy (140). Finally, a case report indicated that a CLL patient on ibrutinib suffered from progressive multifocal leukoencephalopathy (141).

\section{Conclusion}

Ibrutinib, alone or as combination therapy, is effective and well-tolerated in patients with CLL. The safety profile of ibrutinib is manageable. Single-agent or combination therapies can significantly improve outcomes in patients with high-risk disease. In clinical trials and real-world experience, AF, bleeding and infection have emerged as the most challenging complications associated with the use of ibrutinib. Collaboration from multidisciplinary experts (cardiologists, epidemiologists and hepatologists) should be considered to deal with ibrutinib-associated AF, bleeding, infections and HBV reactivation, among others. Candidates for ibrutinib treatment should be provided with an adequate program of surveillance to avoid SAEs and unnecessary discontinuation.

\section{Acknowledgements}

Not applicable.

\section{Funding}

The review was supported by the National Natural Science Foundation of China (grant no. 81560030), the Natural Science Foundation of Jiangxi Province (grant no. 20151BAB205021) and the Natural Science Foundation of Social Development Projects of Jiangxi Province (grant no. 20151BBG70170).

\section{Availability of data and materials}

Not applicable.

\section{Authors' contributions}

FZ initiated the study and wrote the manuscript. LY revised it critically for important intellectual content. QS and AT gave important advice concerning the literature research. JC approved the version to be published. All authors read and approved the manuscript and agree to be accountable for all aspects of the research in ensuring that the accuracy or integrity of any part of the work are appropriately investigated and resolved.

\section{Ethics approval and consent to participate}

Not applicable.

\section{Patient consent for publication}

Not applicable. 


\section{Competing interests}

The authors declare that they have no competing interests.

\section{References}

1. Niiro H and Clark EA: Regulation of B-cell fate by antigenreceptor signals. Nat Rev Immunol 2: 945-956, 2002.

2. Bojarczuk K, Bobrowicz M, Dwojak M, Miazek N, Zapala P, Bunes A, Siernicka M, Rozanska M and Winiarska M: B-cell receptor signaling in the pathogenesis of lymphoid malignancies. Blood Cells Mol Dis 55: 255-265, 2015.

3. Mohamed AJ, Vargas L, Nore BF, Backesjo CM, Christensson B and Smith CI: Nucleocytoplasmic shuttling of Bruton's tyrosine kinase. J Biol Chem 275: 40614-40619, 2000.

4. Hendriks RW, Yuvaraj S and Kil LP: Targeting Bruton's tyrosine kinase in B cell malignancies. Nat Rev Cancer 14: 219-232, 2014.

5. Honigberg LA, Smith AM, Sirisawad M, Verner E, Loury D, Chang B, Li S, Pan Z, Thamm DH, Miller RA, et al: The Bruton tyrosine kinase inhibitor PCI-32765 blocks B-cell activation and is efficacious in models of autoimmune disease and B-cell malignancy. Proc Natl Acad Sci USA 107: 13075-13080, 2010.

6. Small S: Ibrutinib approved for the treatment of mantle cell lymphoma. Clin Adv Hematol Oncol 11: 808, 2013.

7. Dangi-Garimella S: FDA grants accelerated approval for ibrutinib for CLL. Am J Manag Care 20: E10, 2014.

8. Raedler LA: Imbruvica (Ibrutinib): First drug approved for the treatment of patients with Waldenström's macroglobulinemia. Am Health Drug Benefits 9 (Spec Feature): 89-92, 2016.

9. Packard TA and Cambier JC: B lymphocyte antigen receptor signaling: Initiation, amplification, and regulation. F1000Prime Rep 5: 40, 2013.

10. Rickert RC: New insights into pre-BCR and BCR signalling with relevance to B cell malignancies. Nat Rev Immunol 13: 578-591, 2013.

11. Kaur V and Swami A: Ibrutinib in CLL: A focus on adverse events, resistance, and novel approaches beyond ibrutinib. Ann Hematol 96: 1175-1184, 2017.

12. Wang Y, Zhang LL, Champlin RE and Wang ML: Targeting Bruton's tyrosine kinase with ibrutinib in B-cell malignancies. Clin Pharmacol Ther 97: 455-468, 2015.

13. Vetrie D, Vorechovský I, Sideras P, Holland J, Davies A, Flinter F, Hammarström L, Kinnon C, Levinsky R, Bobrow M, et al: The gene involved in X-linked agammaglobulinaemia is a member of the src family of protein-tyrosine kinases. Nature 361: 226-233, 1993.

14. Bruton OC: Agammaglobulinemia. Pediatrics 9: 722-728, 1952.

15. Hagemann TL, Chen Y, Rosen FS and Kwan SP: Genomic organization of the Btk gene and exon scanning for mutations in patients with X-linked agammaglobulinemia. Hum Mol Genet 3: 1743-1749, 1994.

16. Cheng S, Ma J, Guo A, Lu P, Leonard JP, Coleman M, Liu M, Buggy JJ, Furman RR and Wang YL: BTK inhibition targets in vivo CLL proliferation through its effects on B-cell receptor signaling activity. Leukemia 28: 649-657, 2014.

17. Berglöf A, Hamasy A, Meinke S, Palma M, Krstic A, Månsson R, Kimby E,Österborg A and Smith CI: Targets for ibrutinib beyond B cell malignancies. Scand J Immunol 82: 208-217, 2015.

18. Bradshaw JM: The Src, Syk, and Tec family kinases: Distinct types of molecular switches. Cell Signal 22: 1175-1184, 2010.

19. Pan Z, Scheerens H, Li SJ, Schultz BE, Sprengeler PA, Burrill LC, Mendonca RV, Sweeney MD, Scott KC, Grothaus PG, et al: Discovery of selective irreversible inhibitors for Bruton's tyrosine kinase. ChemMedChem 2: 58-61, 2007.

20. Kawakami Y, Kitaura J, Hata D, Yao L and Kawakami T: Functions of Bruton's tyrosine kinase in mast and B cells. J Leukoc Biol 65: 286-290, 1999.

21. Khare A, Viswanathan B, Gund R, Jain N, Ravindran B, George A, Rath S and Bal V: Role of Bruton's tyrosine kinase in macrophage apoptosis. Apoptosis 16: 334-346, 2011

22. Bao Y, Zheng J, Han C, Jin J, Han H, Liu Y, Lau YL, Tu W and Cao X: Tyrosine kinase Btk is required for NK cell activation. $J$ Biol Chem 287: 23769-23778, 2012.

23. Stiff A, Trikha P, Wesolowski R, Kendra K, Hsu V, Uppati S, McMichael E, Duggan M, Campbell A, Keller K, et al: Myeloidderived suppressor cells express Bruton's tyrosine kinase and can be depleted in tumor-bearing hosts by ibrutinib treatment. Cancer Res 76: 2125-2136, 2016.
24. Satterthwaite AB, Li Z and Witte ON: Btk function in B cell development and response. Semin Immunol 10: 309-316, 1998.

25. Küppers R: Mechanisms of B-cell lymphoma pathogenesis. Nat Rev Cancer 5: 251-262, 2005.

26. Buggy JJ and Elias L: Bruton tyrosine kinase (BTK) and its role in B-cell malignancy. Int Rev Immunol 31: 119-132, 2012.

27. Cinar M, Hamedani F, Mo Z, Cinar B, Amin HM and Alkan S: Bruton tyrosine kinase is commonly overexpressed in mantle cell lymphoma and its attenuation by Ibrutinib induces apoptosis. Leuk Res 37: 1271-1277, 2013.

28. Goodman PA, Wood CM, Vassilev AO, Mao C and Uckun FM: Defective expression of Bruton's tyrosine kinase in acute lymphoblastic leukemia. Leuk Lymphoma 44: 1011-1018, 2003.

29. Pal Singh S, Dammeijer F and Hendriks RW: Role of Bruton's tyrosine kinase in B cells and malignancies. Mol Cancer 17: 57, 2018.

30. Brown JR: Ibrutinib (PCI-32765), the first BTK (Bruton's tyrosine kinase) inhibitor in clinical trials. Curr Hematol Malig Rep 8: 1-6, 2013.

31. Singh J, Petter RC and Kluge AF: Targeted covalent drugs of the kinase family. Curr Opin Chem Biol 14: 475-480, 2010.

32. Grabinski N and Ewald F: Ibrutinib (ImbruvicaTM) potently inhibits ErbB receptor phosphorylation and cell viability of ErbB2positive breast cancer cells. Invest New Drugs 32: 1096-1104, 2014.

33. Zucha MA, Wu AT, Lee WH, Wang LS, Lin WW, Yuan CC and Yeh CT: Bruton's tyrosine kinase (Btk) inhibitor ibrutinib suppresses stem-like traits in ovarian cancer. Oncotarget 6: 13255-13268, 2015.

34. Wang JD, Chen XY, Ji KW and Tao F: Targeting Btk with ibrutinib inhibit gastric carcinoma cells growth. Am J Transl Res 8: 3003-3012, 2016.

35. Gao W, Wang M, Wang L, Lu H, Wu S, Dai B, Ou Z, Zhang L, Heymach JV, Gold KA, et al: Selective antitumor activity of ibrutinib in EGFR-mutant non-small cell lung cancer cells. J Natl Cancer Inst 106: dju204, 2014. doi: 10.1093/jnci/dju204.

36. Wei L, Su YK, Lin CM, Chao TY, Huang SP, Huynh TT, Jan HJ, Whang-Peng J, Chiou JF, Wu AT, et al: Preclinical investigation of ibrutinib, a Bruton's kinase tyrosine (Btk) inhibitor, in suppressing glioma tumorigenesis and stem cell phenotypes. Oncotarget 7: 69961-69975, 2016.

37. Wang J, Liu X, Hong Y, Wang S, Chen P, Gu A, Guo X and Zhao P: Ibrutinib, a Bruton's tyrosine kinase inhibitor, exhibits antitumoral activity and induces autophagy in glioblastoma. $\mathrm{J}$ Exp Clin Cancer Res 36: 96, 2017.

38. Rushworth SA, Pillinger G, Abdul-Aziz A, Piddock R, Shafat MS, Murray MY, Zaitseva L, Lawes MJ, MacEwan DJ and Bowles KM: Activity of Bruton's tyrosine-kinase inhibitor ibrutinib in patients with CD117-positive acute myeloid leukaemia: A mechanistic study using patient-derived blast cells. Lancet Haematol 2: e204-e211, 2015.

39. Kim E, Hurtz C, Koehrer S, Wang Z, Balasubramanian S, Chang BY, Müschen M, Davis RE and Burger JA: Ibrutinib inhibits pre-BCR ${ }^{+} \mathrm{B}$-cell acute lymphoblastic leukemia progression by targeting BTK and BLK. Blood 129: 1155-1165, 2017.

40. Deeks ED: Ibrutinib: A Review in chronic lymphocytic leukaemia. Drugs 77: 225-236, 2017.

41. de Zwart L, Snoeys J, De Jong J, Sukbuntherng J, Mannaert E and Monshouwer M: Ibrutinib dosing strategies based on interaction potential of CYP3A4 perpetrators using physiologically based pharmacokinetic modeling. Clin Pharmacol Ther 100: 548-557, 2016.

42. Finnes HD, Chaffee KG, Call TG, Ding W, Kenderian SS, Bowen DA, Conte M, McCullough KB, Merten JA, Bartoo GT, et al: Pharmacovigilance during ibrutinib therapy for chronic lymphocytic leukemia (CLL)/small lymphocytic lymphoma (SLL) in routine clinical practice. Leuk Lymphoma 58: 1376-1383, 2017.

43. FDA U: Imbruvica (ibrutinib) capsules: US prescribing information. http://www.fda.gov.2016.

44. Ltd J-C: Imbruvica $140 \mathrm{mg}$ hard capsules. https://www. medicines.org.uk/emc/medicine/293832018.

45. Herman SEM, Gordon AL, Hertlein E, Ramanunni A, Zhang X, Jaglowski S, Flynn J, Jones J, Blum KA, Buggy JJ, et al: Bruton tyrosine kinase represents a promising therapeutic target for treatment of chronic lymphocytic leukemia and is effectively targeted by PCI-32765. Blood 117: 6287-6296, 2011.

46. Woyach JA, Bojnik E, Ruppert AS, Stefanovski MR, Goettl VM, Smucker KA, Smith LL, Dubovsky JA, Towns WH, MacMurray J, et al: Bruton's tyrosine kinase (BTK) function is important to the development and expansion of chronic lymphocytic leukemia (CLL). Blood 123: 1207-1213, 2014. 
47. Herman SE, Sun X, McAuley EM, Hsieh MM, Pittaluga S, Raffeld M, Liu D, Keyvanfar K, Chapman CM, Chen J, et al: Modeling tumor-host interactions of chronic lymphocytic leukemia in xenografted mice to study tumor biology and evaluate targeted therapy. Leukemia 27: 2311-2321, 2013.

48. O'Brien S, Furman RR, Coutre SE, Sharman JP, Burger JA, Blum KA, Grant B, Richards DA, Coleman M, Wierda WG, et al: Ibrutinib as initial therapy for elderly patients with chronic lymphocytic leukaemia or small lymphocytic lymphoma: An open-label, multicentre, phase 1b/2 trial. Lancet Oncol 15: 48-58, 2014.

49. Burger JA, Tedeschi A, Barr PM, Robak T, Owen C, Ghia P, Bairey O, Hillmen P, Bartlett NL, Li J, et al; RESONATE-2 Investigators: Ibrutinib as initial yherapy for patients with chronic lymphocytic leukemia. N Engl J Med 373: 2425-2437, 2015.

50. Shanafelt TD, Wang V, Kay NE, Hanson CA, O'Brien SM, Barrientos JC, Erba HP, Stone RM, Litzow MR and Tallman MS A Randomized phase III study of ibrutinib (PCI-32765)-based therapy vs. standard fludarabine, cyclophosphamide, and rituximab (FCR) chemoimmunotherapy in untreated younger patients with chronic lymphocytic leukemia (CLL): A trial of the ECOG-ACRIN Cancer Research Group (E1912). Blood 132: LBA-4-LBA-4, 2018

51. Woyach JA, Ruppert AS, Heerema NA, Zhao W, Booth AM, Ding W, Bartlett NL, Brander DM, Barr PM, Rogers KA, et al: Ibrutinib regimens versus chemoimmunotherapy in older patients with untreated CLL. N Engl J Med 379: 2517-2528, 2018

52. Moreno C, Greil R, Demirkan F, Tedeschi A, Anz B, Larratt L, Simkovic M, Samoilova O, Novak J, Ben-Yehuda D, et al: Ibrutinib plus obinutuzumab versus chlorambucil plus obinutuzumab in first-line treatment of chronic lymphocytic leukaemia (iLLUMINATE): A multicentre, randomised, open-label, phase 3 trial. Lancet Oncol 20: 43-56, 2019.

53. Advani RH, Buggy JJ, Sharman JP, Smith SM, Boyd TE, Grant B, Kolibaba KS, Furman RR, Rodriguez S, Chang BY, et al: Bruton tyrosine kinase inhibitor ibrutinib (PCI-32765) has significant activity in patients with relapsed/refractory B-cell malignancies. J Clin Oncol 31: 88-94, 2013

54. Byrd JC, Furman RR, Coutre SE, Flinn IW, Burger JA, Blum KA, Grant B, Sharman JP, Coleman M, Wierda WG, et al: Targeting BTK with ibrutinib in relapsed chronic lymphocytic leukemia. N Engl J Med 369: 32-42, 2013

55. Byrd JC, Brown JR, O'Brien S, Barrientos JC, Kay NE, Reddy NM, Coutre S, Tam CS, Mulligan SP, Jaeger U, et al; RESONATE Investigators: Ibrutinib versus ofatumumab in previously treated chronic lymphoid leukemia. N Engl J Med 371: 213-223, 2014.

56. Byrd JC, Furman RR, Coutre SE, Burger JA, Blum KA, Coleman M, Wierda WG, Jones JA, Zhao W, Heerema NA, et al: Three-year follow-up of treatment-naïve and previously treated patients with CLL and SLL receiving single-agent ibrutinib. Blood 125: 2497-2506, 2015.

57. Coutré SE, Furman RR, Flinn IW, Burger JA, Blum K, Sharman J Jones J, Wierda W, Zhao W, Heerema NA, et al: Extended treatment with single-agent ibrutinib at the $420 \mathrm{mg}$ dose leads to durable responses in chronic lymphocytic leukemia/small lymphocytic lymphoma. Clin Cancer Res 23: 1149-1155, 2017.

58. O'Brien S, Furman RR, Coutre S, Flinn IW, Burger JA, Blum K, Sharman J, Wierda W, Jones J,Zhao W, et al: Single-agent ibrutinib in treatment-naïve and relapsed/refractory chronic lymphocytic leukemia: A 5-year experience. Blood 131: 1910-1919, 2018.

59. Farooqui MZ, Valdez J, Martyr S, Aue G, Saba N, Niemann CU, Herman SE, Tian X, Marti G, Soto S, et al: Ibrutinib for previously untreated and relapsed or refractory chronic lymphocytic leukaemia with TP53 aberrations: A phase 2, single-arm trial. Lancet Oncol 16: 169-176, 2015.

60. Ahn IE, Farooqui MZH, Tian X, Valdez J, Sun C, Soto S, Lotter J, Housel S, Stetler-Stevenson M, Yuan CM, et al: Depth and durability of response to ibrutinib in CLL: 5-year follow-up of a phase 2 study. Blood 131: 2357-2366, 2018

61. O'Brien S, Jones JA, Coutre SE, Mato AR, Hillmen P, Tam C, Österborg A, Siddiqi T, Thirman MJ, Furman RR, et al: Ibrutinib for patients with relapsed or refractory chronic lymphocytic leukaemia with $17 \mathrm{p}$ deletion (RESONATE-17): A phase 2, openlabel, multicentre study. Lancet Oncol 17: 1409-1418, 2016.

62. Jones J, Mato A, Coutre S, Byrd JC, Furman RR, Hillmen P, Osterborg A, Tam C, Stilgenbauer S, Wierda WG, et al: Evaluation of 230 patients with relapsed/refractory deletion $17 \mathrm{p}$ chronic lymphocytic leukaemia treated with ibrutinib from 3 clinical trials. Br J Haematol 182: 504-512, 2018.
63. Winqvist M, Asklid A, Andersson PO, Karlsson K, Karlsson C, Lauri B, Lundin J, Mattsson M, Norin S, Sandstedt A, et al: Real-world results of ibrutinib in patients with relapsed or refractory chronic lymphocytic leukemia: Data from 95 consecutive patients treated in a compassionate use program. A study from the Swedish Chronic Lymphocytic Leukemia Group. Haematologica 101: 1573-1580, 2016.

64. Mato AR, Nabhan C, Barr PM, Ujjani CS, Hill BT, Lamanna N, Skarbnik AP, Howlett C, Pu JJ, Sehgal AR, et al: Outcomes of CLL patients treated with sequential kinase inhibitor therapy: A real world experience. Blood 128: 2199-2205, 2016.

65. Ysebaert L, Aurran-Schleinitz T, Dartigeas C, Dilhuydy MS, Feugier P, Michallet AS, Tournilhac O, Dupuis J, Sinet P, Albrecht C, et al: Real-world results of ibrutinib in relapsed/ refractory CLL in France: Early results on a large series of 428 patients. Am J Hematol 92: E166-E168, 2017.

66. Mato AR, Hill BT, Lamanna N, Barr PM, Ujjani CS, Brander DM, Howlett C, Skarbnik AP, Cheson BD, Zent CS, et al: Optimal sequencing of ibrutinib, idelalisib, and venetoclax in chronic lymphocytic leukemia: Results from a multicenter study of 683 patients. Ann Oncol 28: 1050-1056, 2017.

67. Hillmen P, Diels J, Healy N, Iraqi W, Aschan J and Wildgust M: Ibrutinib for chronic lymphocytic leukemia: International experience from a named patient program. Haematologica 103: e204-e206, 2018.

68. UK CLL Forum: Ibrutinib for relapsed/refractory chronic lymphocytic leukemia: A UK and Ireland analysis of outcomes in 315 patients. Haematologica 101: 1563-1572, 2016.

69. Barr PM, Brown JR, Hillmen P, O'Brien S, Barrientos JC, Reddy NM, Coutre S, Mulligan SP, Jaeger U, Furman RR, et al: Impact of ibrutinib dose adherence on therapeutic efficacy in patients with previously treated CLL/SLL. Blood 129: 2612-2615, 2017.

70. Da Roit F, Engelberts PJ, Taylor RP, Breij EC, Gritti G, Rambaldi A, Introna M, Parren PW, Beurskens FJ and Golay J: Ibrutinib interferes with the cell-mediated anti-tumor activities of therapeutic CD20 antibodies: Implications for combination therapy. Haematologica 100: 77-86, 2015.

71. Hing ZA, Mantel R, Beckwith KA, Guinn D, Williams E, Smith LL, Williams K, Johnson AJ, Lehman AM, Byrd JC, et al: Selinexor is effective in acquired resistance to ibrutinib and synergizes with ibrutinib in chronic lymphocytic leukemia. Blood 125: 3128-3132, 2015.

72. Younes A, Thieblemont C, Morschhauser F, Flinn I, Friedberg JW, Amorim S, Hivert B, Westin J, Vermeulen J, Bandyopadhyay N, et al: Combination of ibrutinib with rituximab, cyclophosphamide, doxorubicin, vincristine, and prednisone (R-CHOP) for treatment-naive patients with CD20-positive B-cell non-Hodgkin lymphoma: A non-randomised, phase 1b study. Lancet Oncol 15: 1019-1026, 2014

73. Burger JA, Keating MJ, Wierda WG, Hartmann E, Hoellenriegel J, Rosin NY, de Weerdt I, Jeyakumar G, Ferrajoli A, CardenasTuranzas M, et al: Safety and activity of ibrutinib plus rituximab for patients with high-risk chronic lymphocytic leukaemia: A single-arm, phase 2 study. Lancet Oncol 15: 1090-1099, 2014

74. Jaglowski SM, Jones JA, Nagar V, Flynn JM, Andritsos LA, Maddocks KJ, Woyach JA, Blum KA, Grever MR, Smucker K, et al: Safety and activity of BTK inhibitor ibrutinib combined with ofatumumab in chronic lymphocytic leukemia: A phase 1b/2 study. Blood 126: 842-850, 2015.

75. Maddocks K, Christian B, Jaglowski S, Flynn J, Jones JA, Porcu P, Wei L, Jenkins C, Lozanski G, Byrd JC, et al: A phase $1 / 1 b$ study of rituximab, bendamustine, and ibrutinib in patients with untreated and relapsed/refractory non-Hodgkin lymphoma. Blood 125: 242-248, 2015.

76. Sharman JP, Farber CM, Mahadevan D, Schreeder MT, Brooks HD, Kolibaba KS, Fanning S, Klein L, Greenwald DR, Sportelli P, et al: Ublituximab (TG-1101), a novel glycoengineered anti-CD20 antibody, in combination with ibrutinib is safe and highly active in patients with relapsed and/or refractory chronic lymphocytic leukaemia: Results of a phase 2 trial. Br J Haematol 176: 412-420, 2017

77. Cervantes-Gomez F, Lamothe B, Woyach JA, Wierda WG, Keating MJ, Balakrishnan K and Gandhi V: Pharmacological and protein profiling suggests venetoclax (ABT-199) as optimal partner with ibrutinib in chronic lymphocytic leukemia. Clin Cancer Res 21: 3705-3715, 2015.

78. Brown JR, Barrientos JC, Barr PM, Flinn IW, Burger JA, Tran A, Clow F, James DF, Graef T, Friedberg JW, et al: The Bruton tyrosine kinase inhibitor ibrutinib with chemoimmunotherapy in patients with chronic lymphocytic leukemia. Blood 125: 2915-2922, 2015 . 
79. Chanan-Khan A, Cramer P, Demirkan F, Fraser G, Silva RS, Grosicki S, Pristupa A, Janssens A, Mayer J, Bartlett NL, et al; HELIOS investigators: Ibrutinib combined with bendamustine and rituximab compared with placebo, bendamustine, and rituximab for previously treated chronic lymphocytic leukaemia or small lymphocytic lymphoma (HELIOS): A randomised, double-blind, phase 3 study. Lancet Oncol 17: 200-211, 2016.

80. Nastoupil L, Lunning MA, Vose JM, Schreeder MT, Siddiqi T, Flowers CR, Cohen JB, Burger JA, Wierda WG, O'Brien S, et al: Chemo-free triplet combination of TGR-1202, ublituximab and ibrutinib is well tolerated and highly active in patients with advanced CLL and NHL. Hematol Oncol 35: 112-113, 2017.

81. Ujjani C, Wang H, Skarbnik A, Trivedi N, Ramzi P, Khan N and Cheson BD: A phase 1 study of lenalidomide and ibrutinib in combination with rituximab in relapsed and refractory CLL. Blood Adv 2: 762-768, 2018.

82. Hershkovitz-Rokah O, Pulver D, Lenz G and Shpilberg O: Ibrutinib resistance in mantle cell lymphoma: Clinical, molecular and treatment aspects. Br J Haematol 181: 306-319, 2018.

83. Furman RR, Cheng S, Lu P, Setty M, Perez AR, Guo A, Racchumi J, Xu G, Wu H, Ma J, et al: Ibrutinib resistance in chronic lymphocytic leukemia. N Engl J Med 370: 2352-2354, 2014.

84. Woyach JA, Ruppert AS, Guinn D, Lehman A, Blachly JS, Lozanski A, Heerema NA, Zhao W, Coleman J, Jones D, et al: BTKC481S-mediated resistance to ibrutinib in chronic lymphocytic leukemia. J Clin Oncol 35: 1437-1443, 2017.

85. Ahn IE, Underbayev C, Albitar A, Herman SE, Tian X, Maric I, Arthur DC, Wake L, Pittaluga S, Yuan CM, et al: Clonal evolution leading to ibrutinib resistance in chronic lymphocytic leukemia. Blood 129: 1469-1479, 2017.

86. Ahn IE, Tian X, Albitar M, Herman SEM, Cook EM, Soto S, Ma W, Ipe D, Tsao LC, Cheng M, et al: Validation of clinical prognostic models and integration of genetic biomarkers of drug resistance in CLL patients treated with ibrutinib. Blood 132: 186-186, 2018

87. Quinquenel A, Fornecker LM, Letestu R, Ysebaert L, Fleury C, Lazarian G, Dilhuydy MS, Nollet D, Guieze R, Feugier P, et al High prevalence of BTK mutations on ibrutinib therapy after 3 years of treatment in a real-life cohort of CLL patients: A study from the French Innovative Leukemia Organization (FILO) Group. Blood 132: 584-584, 2018.

88. Boissard F, Fournié JJ, Quillet-Mary A, Ysebaert L and Poupot M: Nurse-like cells mediate ibrutinib resistance in chronic lymphocytic leukemia patients. Blood Cancer J 5: e355, 2015.

89. Borge M, Belén Almejún M, Podaza E, Colado A, Fernández Grecco H, Cabrejo M, Bezares RF, Giordano M and Gamberale R: Ibrutinib impairs the phagocytosis of rituximab-coated leukemic cells from chronic lymphocytic leukemia patients by human macrophages. Haematologica 100: e140-e142, 2015.

90. Kohrt HE, Sagiv-Barfi I, Rafiq S, Herman SE, Butchar JP, Cheney C, Zhang X, Buggy JJ, Muthusamy N, Levy R, et al: Ibrutinib antagonizes rituximab-dependent NK cell-mediated cytotoxicity. Blood 123: 1957-1960, 2014.

91. Jacobson C, Kopp N, Layer JV, Redd RA, Tschuri S, Haebe S, van Bodegom D, Bird L, Christie AL, Christodoulou A, et al: HSP90 inhibition overcomes ibrutinib resistance in mantle cell lymphoma. Blood 128: 2517-2526, 2016.

92. Srour SA, Lee HJ, Nomie K, Ye H, Chen W, Oriabure O Romaguera J and Wang ML: Novel chemotherapy-free combination regimen for ibrutinib-resistant mantle cell lymphoma. $\mathrm{Br}$ J Haematol 181: 561-564, 2017.

93. Brown JR, Moslehi J, O'Brien S, Ghia P, Hillmen P, Cymbalista F, Shanafelt TD, Fraser G, Rule S, Kipps TJ, et al: Characterization of atrial fibrillation adverse events reported in ibrutinib randomized controlled registration trials. Haematologica 102: 1796-1805, 2017

94. Gustine JN, Meid K, Dubeau TE, Treon SP and Castillo JJ: Atrial fibrillation associated with ibrutinib in Waldenström macroglobulinemia. Am J Hematol 91: E312-E313, 2016.

95. Farooqui M, Valdez J, Soto S, Bray A, Tian X and Wiestner A: Atrial fibrillation in CLL/SLL patients on ibrutinib. Blood 126: 2933-2933, 2015.

96. Leong DP, Caron F, Hillis C, Duan A, Healey JS, Fraser G and Siegal D: The risk of atrial fibrillation with ibrutinib use: A systematic review and meta-analysis. Blood 128: 138-140, 2016.

97. McMullen JR, Boey EJ, Ooi JY, Seymour JF, Keating MJ and Tam CS: Ibrutinib increases the risk of atrial fibrillation, potentially through inhibition of cardiac PI3K-Akt signaling. Blood 124: 3829-3830, 2014
98. Thompson PA, Lévy V, Tam CS, Al Nawakil C, Goudot FX, Quinquenel A, Ysebaert L, Michallet AS, Dilhuydy MS, Van Den Neste E, et al: Atrial fibrillation in CLL patients treated with ibrutinib. An international retrospective study. Br J Haematol 175: 462-466, 2016.

99. Lambert Kuhn E, Levêque D, Lioure B, Gourieux B and Bilbault P: Adverse event potentially due to an interaction between ibrutinib and verapamil: A case report. J Clin Pharm Ther 41: 104-105, 2016

100. Mulligan SP, Ward CM, Whalley D and Hilmer SN: Atrial fibrillation, anticoagulant stroke prophylaxis and bleeding risk with ibrutinib therapy for chronic lymphocytic leukaemia and lymphoproliferative disorders. Br J Haematol 175: 359-364, 2016.

101. Wang ML, Blum KA, Martin P, Goy A, Auer R, Kahl BS, Jurczak W, Advani RH, Romaguera JE, Williams ME, et al: Long-term follow-up of MCL patients treated with single-agent ibrutinib: Updated safety and efficacy results. Blood 126: 739-745, 2015.

102. Vrontikis A, Carey J, Gilreath JA, Halwani A, Stephens DM and Sweetenham JW: Proposed algorithm for managing ibrutinib-related atrial fibrillation. Oncology (Williston Park) 30: 970-974, 980-971, C973, 2016.

103. Thorp BC and Badoux X: Atrial fibrillation as a complication of ibrutinib therapy: Clinical features and challenges of management. Leuk Lymphoma 59: 311-320, 2018.

104.de Weerdt I, Koopmans SM, Kater AP and van Gelder M: Incidence and management of toxicity associated with ibrutinib and idelalisib: A practical approach. Haematologica 102: 1629-1639, 2017.

105. Jones JA, Hillmen P, Coutre S, Tam C, Furman RR, Barr PM, Schuster SJ, Kipps TJ, Flinn IW, Jaeger U, et al: Use of anticoagulants and antiplatelet in patients with chronic lymphocytic leukaemia treated with single-agent ibrutinib. Br J Haematol 178: 286-291, 2017

106. Gribben JG, Bosch F, Cymbalista F, Geisler CH, Ghia P, Hillmen P, Moreno C and Stilgenbauer S: Optimising outcomes for patients with chronic lymphocytic leukaemia on ibrutinib therapy: European recommendations for clinical practice. Br J Haematol 180: 666-679, 2018

107. Levade M, David E, Garcia C, Laurent PA, Cadot S, Michallet AS, Bordet JC, Tam C, Sié P, Ysebaert L, et al: Ibrutinib treatment affects collagen and von Willebrand factor-dependent platelet functions. Blood 124: 3991-3995, 2014.

108. Lipsky AH, Farooqui MZ, Tian X, Martyr S, Cullinane AM, Nghiem K, Sun C, Valdez J, Niemann CU, Herman SE, et al: Incidence and risk factors of bleeding-related adverse events in patients with chronic lymphocytic leukemia treated with ibrutinib. Haematologica 100: 1571-1578, 2015.

109. Kamel S, Horton L, Ysebaert L, Levade M, Burbury K, Tan S, Cole-Sinclair M, Reynolds J, Filshie R, Schischka S, et al: Ibrutinib inhibits collagen-mediated but not ADP-mediated platelet aggregation. Leukemia 29: 783-787, 2015.

110. Dreyling M, Jurczak W, Jerkeman M, Silva RS, Rusconi C, Trneny M, Offner F, Caballero D, Joao C, Witzens-Harig M, et al: Ibrutinib versus temsirolimus in patients with relapsed or refractory mantle-cell lymphoma: An international, randomised, open-label, phase 3 study. Lancet 387: 770-778, 2016.

111. Yun S, Vincelette ND, Acharya U and Abraham I: Risk of atrial fibrillation and bleeding diathesis associated with ibrutinib treatment: A systematic review and pooled analysis of four randomized controlled trials. Clin Lymphoma Myeloma Leuk 17: 31-37.e13, 2017.

112. Treon SP, Tripsas CK, Meid K, Warren D, Varma G, Green R, Argyropoulos KV, Yang G, Cao Y, Xu L, et al: Ibrutinib in previously treated Waldenström's macroglobulinemia. N Engl J Med 372: 1430-1440, 2015.

113. Serebruany VL, Malinin AI, Ferguson JJ, Vahabi J, Atar D and Hennekens $\mathrm{CH}$ : Bleeding risks of combination vs. single antiplatelet therapy: a meta-analysis of 18 randomized trials comprising 129314 patients. Fundam Clin Pharmacol 22: 315-321, 2008

114. Shatzel JJ, Olson SR, Tao DL, McCarty OJT, Danilov AV and DeLoughery TG: Ibrutinib-associated bleeding: Pathogenesis, management and risk reduction strategies. J Thromb Haemost 15: 835-847, 2017.

115. Dubovsky JA, Beckwith KA, Natarajan G, Woyach JA, Jaglowski S, Zhong Y, Hessler JD, Liu TM, Chang BY, Larkin KM, et al: Ibrutinib is an irreversible molecular inhibitor of ITK driving a Th1-selective pressure in T lymphocytes. Blood 122: $2539-2549,2013$ 
116. Ghosh S, Bienemann K, Boztug K and Borkhardt A: Interleukin2 -inducible T-cell kinase (ITK) deficiency - clinical and molecular aspects. J Clin Immunol 34: 892-899, 2014.

117. Kreiniz N, Bejar J, Polliack A and Tadmor T: Severe pneumonia associated with ibrutinib monotherapy for CLL and lymphoma. Hematol Oncol, 2017.

118. Issa N, Arbona-Haddad E, Nevett-Fernandez A, Prestes D, Liakos A, Woolley A, Hammond S, Brown J, Baden L and Marty F: Opportunistic infections (OIs) in patients with hematologic malignancies (HM) treated with Bruton's tyrosine kinase (BTK) and phosphoinositide 3 kinase (PI3K) inhibitors: An 8-year retrospective cohort study. Open Forum Infect Dis 4 (suppl_1): S699, 2017.

119. Chan TS, Au-Yeung R, Chim CS, Wong SC and Kwong YL: Disseminated fusarium infection after ibrutinib therapy in chronic lymphocytic leukaemia. Ann Hematol 96: 871-872, 2017.

120. Ahn IE, Jerussi T, Farooqui M, Tian X, Wiestner A and Gea-Banacloche J: Atypical Pneumocystis jirovecii pneumonia in previously untreated patients with CLL on single-agent ibrutinib. Blood 128: 1940-1943, 2016.

121.Lionakis MS, Dunleavy K, Roschewski M, Widemann BC, Butman JA, Schmitz R, Yang Y, Cole DE, Melani C, Higham CS, et al: Inhibition of $\mathrm{B}$ cell receptor signaling by ibrutinib in orimary CNS lymphoma. Cancer Cell 31: 833-843.e835, 2017.

122. Diamantopoulos PT, Psichogiou M, Pantazatou A, Zervakis K, Rougala N, Giannakopoulou N, Daikos G and Viniou NA: Staphylococcus aureus meningitis in a patient with mantle cell lymphoma under treatment with ibrutinib. Ann Hematol 96: 1049-1050, 2017.

123. Tillman BF, Pauff JM, Satyanarayana G, Talbott M and Warner JL: Systematic review of infectious events with the Bruton tyrosine kinase inhibitor ibrutinib in the treatment of hematologic malignancies. Eur J Haematol, 2017.

124. Varughese T, Taur Y, Cohen N, Palomba ML, Seo SK, Hohl TM and Redelman-Sidi G: Serious infections in patients receiving ibrutinib for treatment of lymphoid cancer. Clin Infect Dis 67: 687-692, 2018.

125.Ghez D, Calleja A, Protin C, Baron M, Ledoux MP, Damaj G, Dupont M, Dreyfus B, Ferrant E, Herbaux C, et al; French Innovative Leukemia Organization (FILO) CLL group: Early-onset invasive aspergillosis and other fungal infections in patients treated with ibrutinib. Blood 131: 1955-1959, 2018.

126. Wang SY, Ebert T, Jaekel N, Schubert S, Niederwieser D and Al-Ali HK: Miliary tuberculosis after initiation of ibrutinib in chronic lymphocytic leukemia. Ann Hematol 94: 1419-1420, 2015.

127. Sun C, Tian X, Lee YS, Gunti S, Lipsky A, Herman SE, Salem D, Stetler-Stevenson M, Yuan C, Kardava L, et al: Partial reconstitution of humoral immunity and fewer infections in patients with chronic lymphocytic leukemia treated with ibrutinib. Blood 126: 2213-2219, 2015.

128. Yin Q, Sivina M, Robins H, Yusko E, Vignali M, O'Brien S, Keating MJ, Ferrajoli A, Estrov Z, Jain N, et al: Ibrutinib therapy Increases $T$ cell repertoire diversity in patients with chronic lymphocytic leukemia. J Immunol 198: 1740-1747, 2017.
129. Yeo W, Chan TC, Leung NW, Lam WY, Mo FK, Chu MT, Chan HL, Hui EP, Lei KI, Mok TS, et al: Hepatitis B virus reactivation in lymphoma patients with prior resolved hepatitis B undergoing anticancer therapy with or without rituximab. J Clin Oncol 27: 605-611, 2009.

130. Yeo W and Johnson PJ: Diagnosis, prevention and management of hepatitis B virus reactivation during anticancer therapy. Hepatology 43: 209-220, 2006.

131. de Jésus Ngoma P, Kabamba B, Dahlqvist G, Sempoux C, Lanthier N, Shindano T, Van Den Neste E and Horsmans Y: Occult HBV reactivation induced by ibrutinib treatment: A case report. Acta Gastroenterol Belg 78: 424-426, 2015.

132. Herishanu Y, Katchman $\mathrm{H}$ and Polliack A: Severe hepatitis B virus reactivation related to ibrutinib monotherapy. Ann Hematol 96: 689-690, 2017.

133. Tedeschi A, Frustaci AM, Mazzucchelli M, Cairoli R and Montillo M: Is HBV prophylaxis required during CLL treatment with ibrutinib? Leuk Lymphoma 58: 2966-2968, 2017.

134. Wang ML, Rule S, Martin P, Goy A, Auer R, Kahl BS, Jurczak W, Advani RH, Romaguera JE, Williams ME, et al: Targeting BTK with ibrutinib in relapsed or refractory mantle-cell lymphoma. N Engl J Med 369: 507-516, 2013.

135. Ujjani CS, Jung SH, Pitcher B, Martin P, Park SI, Blum KA, Smith SM, Czuczman M, Davids MS, Levine E, et al: Phase 1 trial of rituximab, lenalidomide, and ibrutinib in previously untreated follicular lymphoma: Alliance A051103. Blood 128: 2510-2516, 2016.

136. Mannis G, Wu D, Dea T, Mauro T and Hsu G: Ibrutinib rash in a patient with $17 \mathrm{p}$ del chronic lymphocytic leukemia. Am J Hematol 90: 179, 2015

137. Jensen AB, Stausbøl-Grøn B, Riber-Hansen R and d'Amore F: Ibrutinib-associated skin toxicity: A case of maculopapular rash in a 79-year old Caucasian male patient with relapsed Waldenstrom's macroglobulinemia and review of the literature. Dermatol Rep 9: 6976, 2017.

138. Iberri DJ, Kwong BY, Stevens LA, Coutre SE, Kim J, Sabile JM and Advani RH: Ibrutinib-associated rash: A single-centre experience of clinicopathological features and management. $\mathrm{Br}$ J Haematol, 2016.

139. Neffendorf JE, Gout I and Hildebrand GD: Ibrutinib in relapsed chronic lymphocytic leukemia. N Engl J Med 369: 1277-1279, 2013.

140. Wallace N, Wong E, Cooper D and Chao H: A case of new-onset cardiomyopathy and ventricular tachycardia in a patient receiving ibrutinib for relapsed mantle cell lymphoma. Clin Case Rep 4: 1120-1121, 2016.

141.Lutz M, Schulze AB, Rebber E, Wiebe S, Zoubi T, Grauer OM, Keßler T, Kerkhoff A, Lenz G and Berdel WE: Progressive multifocal leukoencephalopathy after ibrutinib therapy for chronic lymphocytic leukemia. Cancer Res Treat 49: 548-552, 2017. 